\title{
Microstructural and Mechanical Aspects of AlSi7Mg0.6 Alloy Related to Scanning Strategies in L-PBF
}

Pinku Yadav ( $\nabla$ pinku.yadav@u-bordeaux.fr)

Rue du Bois Saint-Jean 12 https://orcid.org/0000-0002-4014-627X

Olivier Rigo

Rue du Bois Saint-Jean 12

\section{Corinne Arvieu}

Université Bordeaux

\section{Eric Lacoste}

Université Bordeaux

\section{Research Article}

Keywords: Laser powder bed fusion, Quality assurance, Residual Stresses, Crystallographic Texture

Posted Date: December 28th, 2021

DOI: https://doi.org/10.21203/rs.3.rs-1178346/v1

License: (9) This work is licensed under a Creative Commons Attribution 4.0 International License. Read Full License

Version of Record: A version of this preprint was published at The International Journal of Advanced Manufacturing Technology on April 6th, 2022. See the published version at https://doi.org/10.1007/s00170-022-09127-x. 


\section{Microstructural and Mechanical aspects of AlSi7Mg0.6 Alloy related to Scanning Strategies in L-PBF

\author{
Pinku Yadav ${ }^{a, b}$, Olivier Rigo ${ }^{a}$, Corinne Arvieu ${ }^{b}$, Eric Lacoste $^{b^{*}}$
}

${ }^{a}$ SIRRIS, Rue du Bois Saint-Jean 12, 4102 Seraing, Belgium

bUniversité Bordeaux, 12M, UMR 5295, CNRS, F-33400 Talence, France

*Corresponding Author: Eric.lacoste@u-bordeaux.fr

\section{Abstract}

AlSi7Mg0.6 alloy is the most widely used cast alloy for aerospace and automotive applications. Therefore, it is essential to explore the effect of scanning strategies parameters on the final part properties in the L-PBF process. The effect of stripes and chessboard strategies parameters such as stripes length, rotation angle, and chessboard island size on mechanical and microstructural properties of L-PBF processed A1Si7Mg0.6 alloy is studied. The evolution of the residual stresses is also investigated in the longitudinal and transverse directions. Cooling rates are also estimated using the cell size within the melt pool. Three distinct regions (i.e., fine, coarse, and heat affected zone) within the melt pool corresponding to different cooling rates could be identified based on Si morphology. The texture of the final material can be tailored by changing the scanning strategies. This study comprehensively presents the results concerning porosity, mechanical properties, crystallographic texture, cooling rates, grain morphology, and residual stresses for additively manufactured AlSi7Mg0.6 alloy.

Keywords: Laser powder bed fusion, Quality assurance, Residual Stresses, Crystallographic Texture

\section{Introduction}

The L-PBF process is of great interest to manufacturing due to its capability and adaptability to fabricate a new complex part. But one of the most significant disadvantages of the L-PBF process is that it takes a lot of time and experiments to find best-fit process parameters for new material. In the L-PBF process, many parameters such as laser power, scanning speed, hatch distance, layer thickness, and scanning strategy can strongly influence the final part properties. Therefore, optimizing and exploring the influence of each parameter is of vital importance in achieving desired microstructural and mechanical properties [1], [2]. Scanning 
strategy representing the spatial motion of the input energy (laser or electron beam) can influence the thermal gradient in a layer, affecting the overall part quality [3]. Several critical defects such as residual stresses, lack of fusion, and balling can be tailored by adapting suitable scanning strategies [4]. Various parameters such as scan vector length, scanning pattern, and scan vector rotation need to be optimized to achieve desired part properties. The different scanning patterns are as follows:

1. Uni-directional scanning: It is a scanning pattern in which the energy source scans the surface as single adjacent scan vectors moving in the same direction.

2. Bi-directional scanning: It is also referred to as "zig-zag scan," It is principally similar to uni-directional. The only difference is that adjacent scan vectors are in opposite directions to each other.

3. Chessboard scanning: The scan area is divided into small square cells similar to the chessboard, and the energy source scans individual cells. The length, rotation, and scanning direction of the individual cells can be varied. The size of the scan vectors is comparatively smaller than the above-discussed strategies. This helps to optimize the residual stresses in the final part.

4. Stripes scanning: It is similar to uni-directional or bi-directional strategies. The only difference is that the scan area is divided into small stripes with smaller individual scan vectors. The rotation between consecutive layers can be applied too. Also, it is the most common scanning strategy in the L-PBF process.

The above-presented scanning strategies significantly affect the thermal gradient, cooling rate, and heat flow of the individual layers, resulting in a change in crystallographic texture, grain size, solidification cell size, and grain aspect ratio for the building part [5]-[7]. Generally, higher cooling rates and a lower ratio of a thermal gradient to solidification rate lead to lower texture strength due to columnar to equiaxed transition (CET) [6], [8].

Apart from microstructural changes, the scanning strategies also partly influence the residual stresses' evolution, which can be detrimental if not optimized. Dunbar et al. [9] reported that the residual stresses are reduced by applying rotation between consecutive layers. Cheng et al. showed that the residual stresses are higher in the longitudinal direction (along the scan vector direction) compared to the transverse direction [10], [11]. Also, the longitudinal stresses increase with an increase in the scan vector length, so it can be concluded that the long scan 
vectors can lead to distortion in part [12]. Kruth et al. [13] and Mercelis et al. [14] reported that the island's size in chessboard strategy does not affect the residual stresses. Contrary to that, $\mathrm{Lu}$ et al. [2] observed that island size of $2 * 2 \mathrm{~mm}^{2}$ has the lowest residual stresses followed by $5 * 5 \mathrm{~mm}^{2}, 7 * 7 \mathrm{~mm}^{2}$, and $3 * 3 \mathrm{~mm}^{2}$ for SLMed IN718 alloy. So, it can be concluded that the evolution of residual stresses in chessboard strategy is not well understood.

Al-Si alloys are excellent materials for casting and are historically used for sand casting. It shows good corrosion resistance, good weldability, and mechanical properties. In the L-PBF process, AlSi10Mg and AlSi12Mg are the most commonly used material and extensively studied by researchers. But recently, AlSi7Mg0.6 also being used as a potential candidate for the L-PBF process [15]. Recently, a study has been reported on investigations of the best-fit parameters to obtain fully dense parts [16]. Other authors have identified the links between the distribution of Si particles in SLM samples and the mechanical properties [17]. But not many studies are available on investigating the effect of scanning strategies on the microstructure, residual stresses, and mechanical properties of AlSi7Mg0.6 which is the aim of this paper.

\section{Experimental Set up}

\subsection{Material}

The AlSi7Mg0.6 powder with composition summarized in Table 1 is used for this study; supplied from SLM Solutions had a spherical morphology with a particle size distribution of Table 1: Elemental composition of as received AISi7Mg0.6 powder (All the values are given in wt. \%).

\begin{tabular}{llllllllll}
\hline Element & $\mathrm{Al}$ & $\mathrm{Cu}$ & $\mathrm{Fe}$ & $\mathrm{Mg}$ & $\mathrm{Mn}$ & $\mathrm{Si}$ & $\mathrm{Ti}$ & $\mathrm{Zn}$ & Others \\
\hline
\end{tabular}

$20-63 \mu \mathrm{m}$ and an average diameter of $41.88 \mu \mathrm{m}$. The powder is kept in air-tight containers, and humidity is checked before printing. The powder's apparent density is $1.53 \mathrm{~g} / \mathrm{cm}^{3}$. 


\begin{tabular}{|c|c|c|c|c|c|c|c|c|c|}
\hline $\begin{array}{l}\text { Minimum [wt } \\
\% \text { ] }\end{array}$ & Balance & - & - & 0.45 & - & 6.50 & - & - & - \\
\hline Actual [wt \%] & Balance & $<0.01$ & 0.08 & 0.55 & $<0.01$ & 6.90 & 0.07 & 0.01 & $<0.03$ \\
\hline Maximum [wt & Balance & 0.05 & 0.19 & 0.70 & 0.10 & 7.50 & 0.25 & 0.07 & 0.03 \\
\hline \%] & & & & & & & & & \\
\hline
\end{tabular}

\subsection{Machine and Process Parameters}

The commercial SLM $280^{\mathrm{HL}}$ (SLM Solutions Group AG, Lübeck, Germany) is equipped with $700 \mathrm{~W}$ twin continuous wave (CW) ytterbium fiber lasers with an emitting wavelength of $1070 \mathrm{~nm}$ spot diameter of $115 \mu \mathrm{m}$ is used for printing. The build envelope volume is $280 * 280 * 365 \mathrm{~mm}^{3}$, and the build chamber is maintained in the Ar gas environment with an oxygen level below $0.1 \%$. The Aluminium base plate is preheated to $150{ }^{\circ} \mathrm{C}$ before printing to reduce thermal stresses in part [18]. The chessboard and stripes scanning strategies are used with varying stripes and chessboard island sizes. The rotation between two consecutive layers is also changed between $0^{\circ}$ to $90^{\circ}$. The process parameters and the sample's nomenclature are tabulated in Table 2 and Table 3, respectively.

Table 2: Process parameters used in this study.

\begin{tabular}{ll}
\hline Varied Parameter & Values \\
\hline Power $(\mathbf{W})$ & 350 \\
\hline Scanning speed $(\mathrm{mm} / \mathbf{s})$ & 1650 \\
\hline Hatch distance $(\mathbf{m m})$ & 0.13 \\
\hline Layer thickness $(\mathbf{m m})$ & 0.03 \\
\hline Scanning strategy & Stripes, Chessboard \\
\hline Rotation in layers for Stripes $\left({ }^{\circ}\right)$ & $45,67,90$ \\
\hline Rotation in layers for Chessboard $\left({ }^{\circ}\right)$ & 0,45, and 90 \\
\hline Stripes Size/Island Size $(\mathbf{m m})$ & $5,10 / 2 * 2,3 * 3,5 * 5$, \\
& $10 * 10$ \\
\hline
\end{tabular}

Table 3: Nomenclature of the samples used in this study.

\begin{tabular}{lllll}
\hline S.No. & $\begin{array}{l}\text { Scanning } \\
\text { Strategy }\end{array}$ & $\begin{array}{l}\text { Size } \\
\mathbf{( m m )}\end{array}$ & Rotation ( & Sample ID \\
\hline $\mathbf{1}$ & Stripes & 5 & 67 & S_5_67 \\
\hline $\mathbf{2}$ & Stripes & 10 & 67 & S_10_67 \\
\hline $\mathbf{3}$ & Stripes & 10 & 90 & S_10_90 \\
\hline $\mathbf{4}$ & Stripes & 10 & 45 & S_10_45 \\
\hline $\mathbf{5}$ & Chessboard & $2 * 2$ & No & C_2*2_no \\
\hline $\mathbf{6}$ & Chessboard & $3 * 3$ & No & C_3*3_no \\
\hline $\mathbf{7}$ & Chessboard & $5 * 5$ & No & C_5*5_no \\
\hline $\mathbf{8}$ & Chessboard & $10 * 10$ & No & C_10*10_no \\
\hline $\mathbf{9}$ & Chessboard & $5 * 5$ & 45 & C_5*5_45 \\
\hline
\end{tabular}




10 Chessboard 10*10 90 C_10*10_90

The $0^{\circ}, 45^{\circ}, 67^{\circ}$, and $90^{\circ}$ alternating strategy procedure involves turning the orientation of each over-building layer by $0^{\circ}$ (Figure $1 \mathrm{~b}$ ), $45^{\circ}$ (Figure 1d), $67^{\circ}$ (Figure 1a), and $90^{\circ}$ (Figure
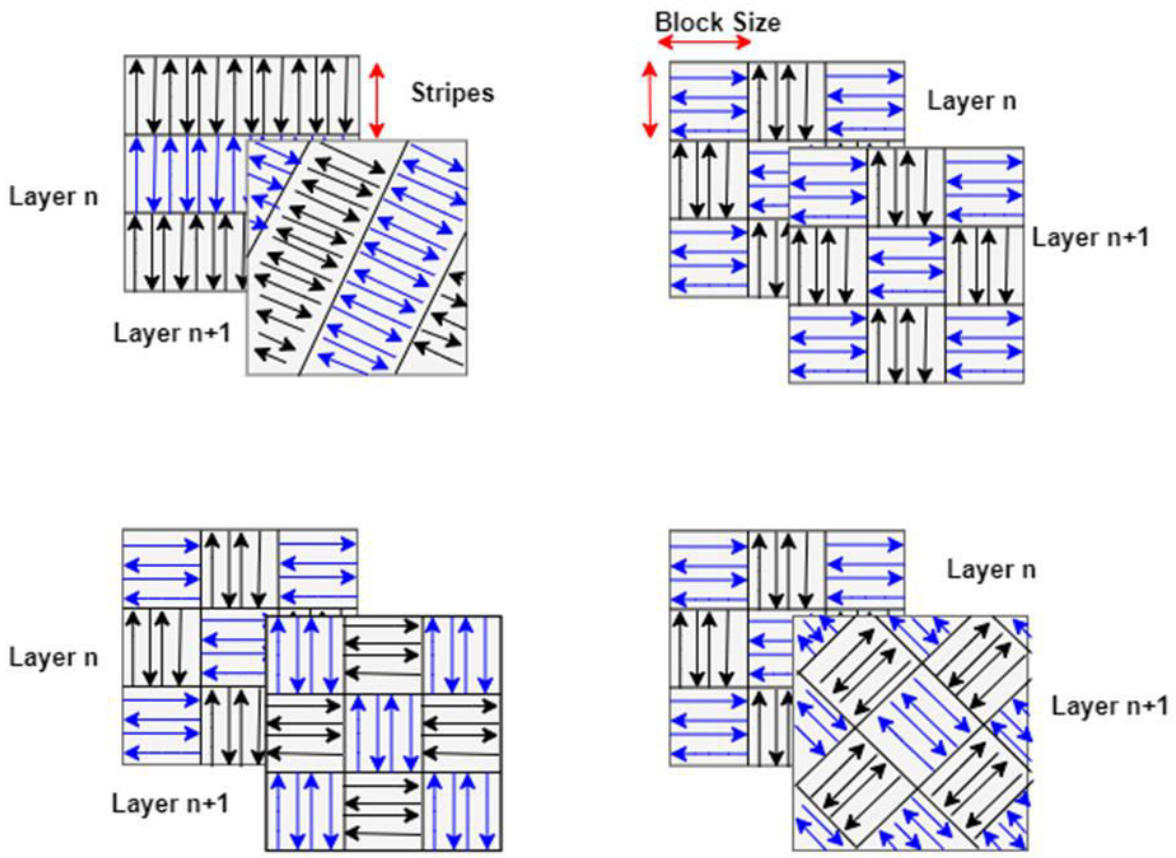

Figure 1: Schematic of the scanning strategies (a) stripes with rotation of $67^{\circ},(b)$ chessboards with $\left(0^{\circ}\right)$ no rotation, (c) chessboards with $90^{\circ}$ rotation, and (d) chessboards with $45^{\circ}$ rotation.

1c) respectively.

\subsection{Test Samples}

Three different geometrical types of AlSi7Mg0.6 test samples are printed for this study:

- For microstructural and density measurements: cubes with dimensions $10 * 10 * 10$ $\mathrm{mm}^{3}$

- For hardness measurements: cubes with dimensions $15 * 10 * 10 \mathrm{~mm}^{3}$;

- $\quad$ For tensile and residual stress measurements: cylinder with a diameter of $16 \mathrm{~mm}$ and length of $55 \mathrm{~mm}$ printed in $\mathrm{X}-\mathrm{Y}$ plane;

\section{Experimental Investigations}

\subsection{Porosity}

Porosity measurements are conducted based on the archimedes principle [19]. It is the most often used method for quickly analyzing the porosity of printed parts. An average of 3 samples is used to conclude the average porosity level. 


\subsection{Hardness}

Vickers hardness tests are conducted according to B EN ISO 6507-1:2005 standard [20] using a load of $5 \mathrm{~kg}$. An average of 5 indentations is taken along the $\mathrm{X}-\mathrm{Z}$ plane (building direction) of each sample's $15 * 10 * 10 \mathrm{~mm}^{3}$ block cross section.

\subsection{Tensile tests}

The tensile samples are machined out from the cylinders of diameter $16 \mathrm{~mm}$ and length 55 mm printed horizontally (X-Y plane). Tensile tests are performed per the ASTM- E8/E8M13a standard [21]. Tensile tests are performed at a $0.5 \mathrm{~mm} / \mathrm{min}$ crosshead displacement rate using an Instron 5567B723 with clip-on extensometers based on BS EN ISO6892-1 standard. The yield stress is calculated at the 0.2 strain of the stress-strain curve.

\subsection{Micrographic examination and SEM}

The microstructure of the SLMed samples is observed by using Scanning Electron Microscope (Carl Zeiss NTS GmbH, Germany). Also, crystallographic orientations investigations are carried out by the electron backscatter diffraction (EBSD) technique. All the samples are mirror polished before microstructural investigations. For SEM observations, samples are chemically etched with Keller's solution $(95 \mathrm{~mL} \mathrm{H} 2 \mathrm{O}, 2.5 \mathrm{~mL}$ HNO3, $1.5 \mathrm{~mL}$ $\mathrm{HCl}$, and $1.0 \mathrm{~mL} \mathrm{HF}$ ) for $10 \mathrm{~s}$. Whereas, for EBSD observations (secondary electron imaging mode), the polished samples are electrochemically polished at $20 \mathrm{~V}$ for $10 \mathrm{~s}$ with a Bruker solution. EBSD analysis is carried out on a cross-section of $200 * 200 \mu \mathrm{m}^{2}$ and at a step size of $1.5 \mu \mathrm{m}$. The samples directions are marked as building direction (BD), transverse direction (TD), and scanning direction (SD).

\subsection{Cooling rate}

During solidification, the cooling rate is an essential factor for the development of the final microstructure. Therefore, it is interesting to find the cooling rate variation in each scanning direction. It is a challenging and complex task to measure the cooling rates experimentally. Usually, analytical solutions are implemented to predict the cooling rates, such as the Rosenthal equation.

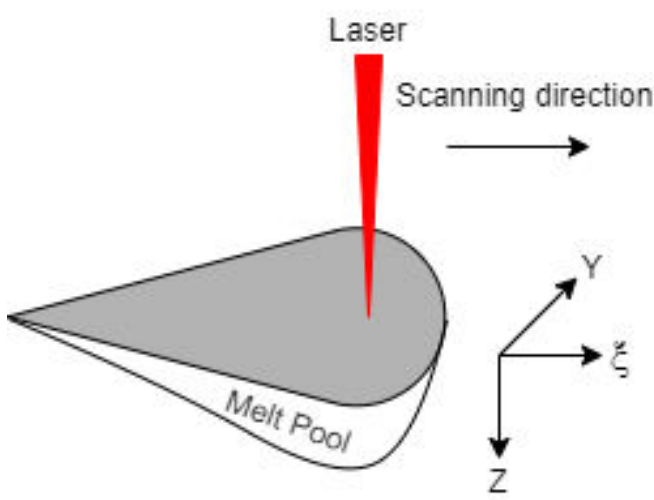


Rosenthal equation [22] is used to estimate the thermal history for the melt pool (Equation 1):

$$
T=T_{0}+\frac{Q}{2 \Pi k} \exp \left[\frac{-V(\xi+R)}{2 \alpha}\right]
$$

Equation 1

Where, $T$ : local temperature, $T_{0}$ : plate temperature, $Q$ : heat input, $R$ : radial distance from the laser source (given by $\mathrm{r}=\left(\xi^{2}+\mathrm{Y}^{2}+\mathrm{Z}^{2}\right)^{1 / 2}$, i.e., $\xi, \mathrm{Y}$ and $\mathrm{Z}$ directions are illustrated in Figure 2), $V$ : beam scanning speed, $\alpha$ : thermal diffusivity (given by $k / \rho C$, where $\rho$ and $C$ are the density and specific heat of the workpiece, respectively)

Although the Rosenthal equation gives the 3-dimensional thermal distribution in the semiinfinite plate for the melt pool case, it has limitations. For example, it only considers conduction and neglecting the heat of fusion. Also, it considers only temperature-independent properties and does not consider the remelting phenomenon occurring in L-PBF [22]. The Rosenthal equation cannot be used to estimate the temperature inside the melt pool as the convection currents decrease the temperature gradient, which is not considered in the analytical equations. Rosenthal equations are suitable for calculating melt pool profiles in the conduction zone, i.e., outside the melt pool. But the analytical equations cannot be used for the full description of thermal histories. Still, they can be used to estimate the average surface cooling rate between the solidus and liquidus at the end of the melt pool long the scanning direction $(\mathrm{Y}=\mathrm{Z}=0)[23]$.

$$
\dot{T}=2 \Pi k\left(T_{\text {solidus }}-T_{0}\right)\left(T_{\text {liquidus }}-T_{0}\right) \frac{V}{Q}
$$

Equation 2

where $\dot{\mathrm{T}}$ is the cooling rate, $T_{\text {solidus }}$ and $T_{\text {liquidus }}$ are the liquidus and solidus temperatures, and $T_{0}$ is the plate temperature.

But for our study, we have calculated the cooling rates within the melt pool using Equation 1 (cell) as the analytical solution only works outside the melt pool.

\subsection{Cell size measurement}

SEM images of the $\mathrm{X}-\mathrm{Z}$ cross-section are used to calculate the cell size, also known as the dendritic arm spacing, directly related to the cooling rate. The relationship between the cell size and cooling rate is expressed by Equation 3. Cell size is measured into the met pool for 
each scanning condition. Apart from the narrow heat-affected zone, the cells appeared uniform through the melt pool (therefore, reheating effect from multiple passes is neglected) and can easily be measured using ImageJ. For each sample, an average of 100 cell measurements from 10 melt pools is used to evaluate the cell size variation in the melt pool.

The relationship between the dendritic arm spacing and cooling rate is expressed as (Equation 3) $[24]$

$$
\lambda_{1}=a \dot{T}^{-n}
$$

Equation 3

where $\lambda_{1}$ is primary dendrite arm spacing or cell size, $\dot{\mathrm{T}}$ is the local cooling rate, and $\mathrm{a}=43.2$ [23] and $\mathrm{n}$ are proportional constants.

The value of $\mathrm{n}$ is in the range 0.32 to 0.38 for cellular morphology and 0.21 for dendritic microstructure [25]. Similarly, the value of $n$ is 0.33 for secondary arm spacing. In L-PBF process, the solidification rate is associated with the laser scan speed. High solidification rate leads to higher cooling rates which leads to cellular microstructures for near eutectic Al-Si alloys in L-PBF process where solidification rates are greater than $0.2 \mathrm{~m} / \mathrm{s}$ [26].

\subsection{Residual stress measurements by $\mathrm{X}$-ray diffraction technique}

The residual stress measurements are conducted using the non-destructive X-ray diffraction technique, which involves measuring the diffraction angle of rays returning to the detector. The diffraction angle is directly related to the distance between atoms of material as the interatomic distance between two atoms reduces compressive residual stresses develops and vice versa for tensile stresses. The residual stresses are calculated using the " $\sin ^{2} \psi$ " technique described in the DIN EN 15305:2009 standard, which involves monitoring the change in diffraction angles due to variation in the incident beam angles. The measurements are performed on the as-built surface and at $2 \mathrm{~mm}$ depth of the samples using the Xstress 3000 G2R instrument. A collimator of size $3 \mathrm{~mm}$ and a $\mathrm{Cr}$ tube as an $\mathrm{x}$-ray generation source are used.

\section{Results and Discussion}


It can be seen from Figure $3 a$ that the samples with stripes $\left(\mathrm{S} \_5 \_67, \mathrm{~S} \_10 \_67, \mathrm{~S} \_10 \_45\right.$, S_10_90) have the lowest porosity levels ranging from 0.83 to $0.99 \%$, whereas the chessboard strategy contributes higher porosity ranging from 0.91 to $2.35 \%$. But there is no significant effect of stripes size and rotation angles on porosity level observed in the case of stripes. Whereas the rotation angle has an effect on porosity level in chessboard strategy. For example, chessboard samples without rotation i.e. C_5*5_no, C_10*10_no has porosity levels $1.48 \%$ and $1.42 \%$ where chessboard samples with rotation i.e. C_5*5_45, C_10*10_90 has porosity levels of $0.91 \%$ and $0.94 \%$. Similarly, the chessboard island with smaller island sizes is more porous compared to the large island sizes. For instance, C_ $2 * 2$ _no, C_ $3 * 3$ _no has porosity levels of $2.35 \%, 2.03 \%$ in comparison with samples C_5*5_no, C_10*10_no has porosity levels of $1.48 \%, 1.42 \%$. The higher porosity level in chessboard samples is linked to the lack of fusion porosity at the junction of the islands, as shown in Figure 4. This phenomenon can be explained as: When the laser hits the powder bed, it creates a denudation zone along the scan vector. At some places near the edges of the islands, there may be the case that there is not enough powder for island bonding leading to porosity at the junction.

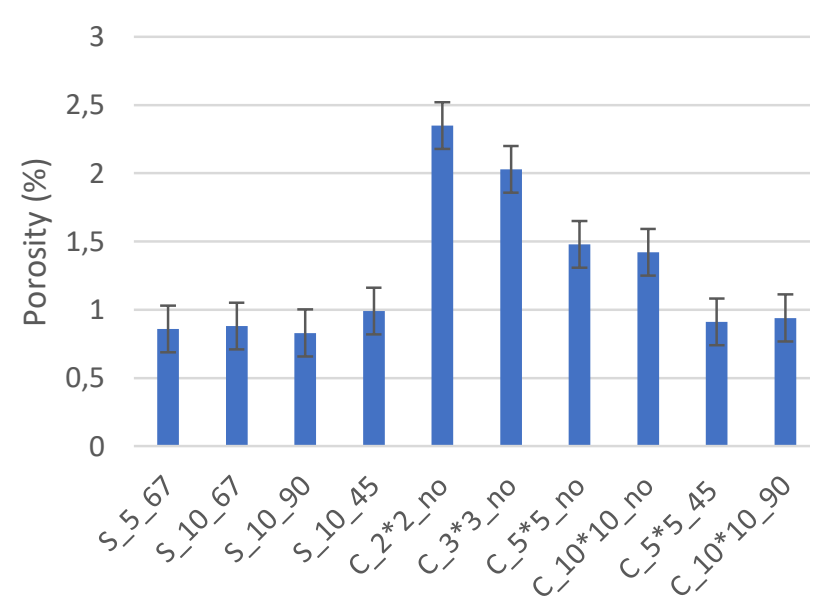

(a)

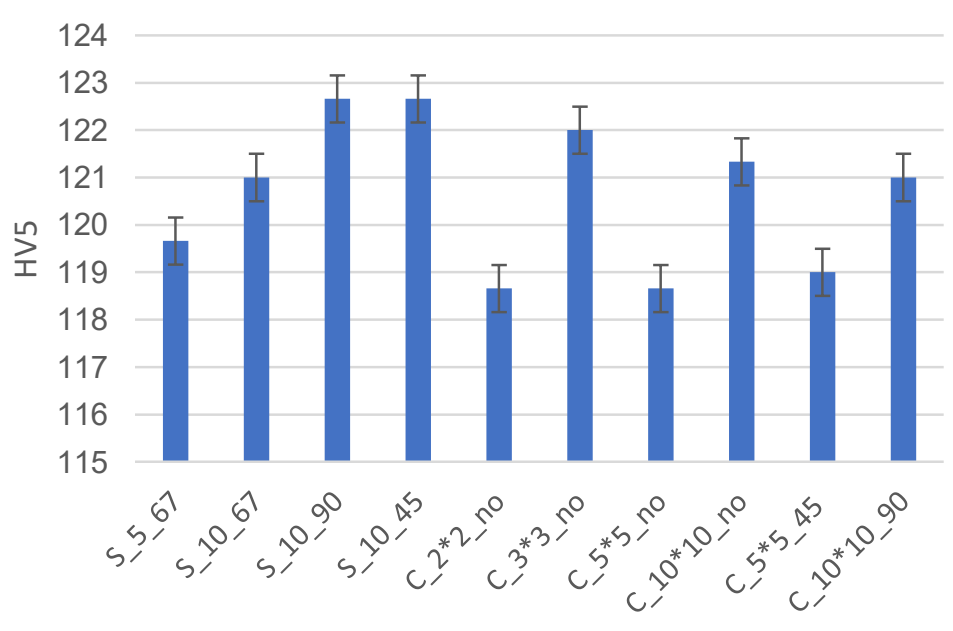

(b)

Figure 3: Effect of scanning strategies on (a) porosity (b) vicker's hardness. 


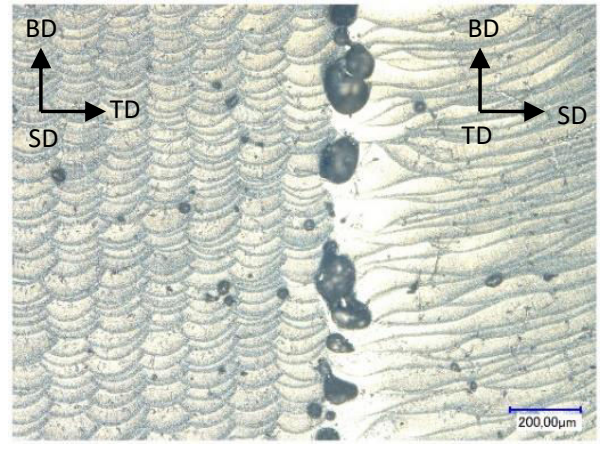

(a)

(c)

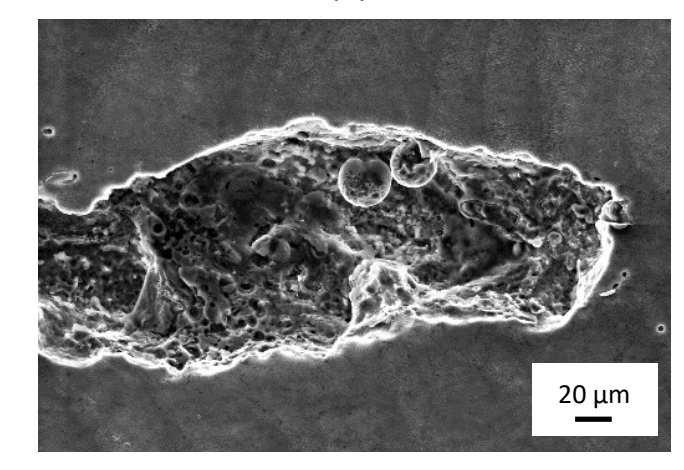

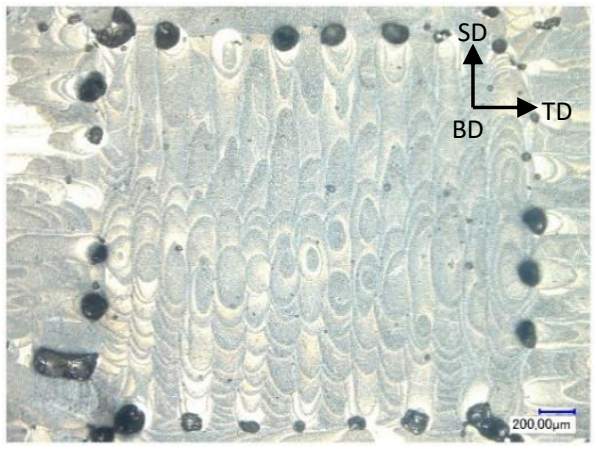

(b)

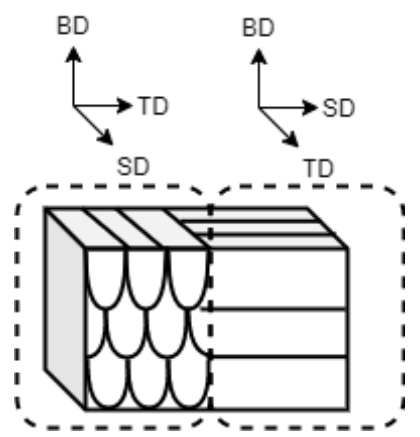

(d)

Figure 4: Optical micrograph of C_10*10_90 sample in (a) building direction, (b) transverse direction, (c) SEM image of LOF defect observed at the junction of the island, and (d) sample orientation.

As smaller island sizes, samples have a higher number of islands than large island sizes, leading to higher porosity in the samples. Figure $3 \mathrm{~b}$ shows that scanning strategies have no considerable effect on the Vickers hardness of the samples. The slight variation between stripes and chessboard strategies could be due to measurement errors or the variation of indentation location on the samples for Vickers hardness. But there is no significant change observed for rotation angle in Stripes and similarly, no pattern observed for chessboard strategies. Chessboard samples reported generally lower hardness values compared to stripes due to higher porosity levels in these samples, but no conclusive trend could be observed. Ali et al. [27] reported similar findings for SLMed Ti6AL4V samples.

It can be seen from Figure 5 that the scanning strategy does not affect the yield strength of SLM AlSi7Mg0.6 samples considerably, and the slight variation can be attributed to the stochastic nature of the process. The elongation \% shows a clear transition from stripes and chessboard strategies. The stripes have an elongation of $13 \%$ for stripe size 10 regardless of rotation with a maximum of $17 \%$ for stripe size 5 . In contrast, the chessboard strategy without rotation shows the lowest elongation of $0.45 \%$, similar to the porosity trend. With the chessboard strategy with rotation, the elongation increases until 10\% which is still lower than the elongations obtained with the stripe strategy. It also suggests that the rotation between 
layers improves the elongation \%, but there is no visible trend for stripes and island size variation. Similarly, the chessboard strategy without rotation has the lowest tensile strength, but no visual effect of the scanning strategy with rotation could be observed.

Interestingly, most of the samples (except for samples with chessboard strategies without rotation) have a better yield strength and elongation \% than as-cast $\mathrm{Al}-\mathrm{Si}$, which has a yield strength of 120-140 MPa and elongation of 1-2 \% [28], [29].

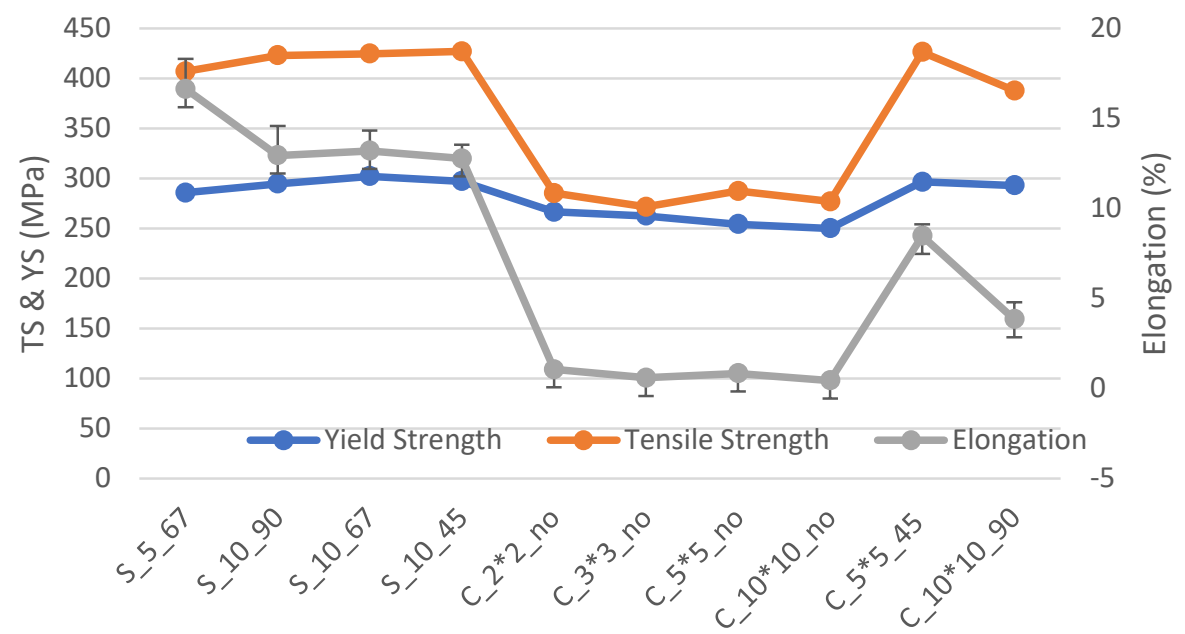

Figure 5. Effect of the scanning strategies on yield strength, ductility, tensile strength.

\subsection{Microstructural Investigations}

\subsubsection{Phase morphology}

$\mathrm{AlSi} 7 \mathrm{Mg} 0.6$ is a hypoeutectic alloy that primarily shows $\alpha$-Al matrix surrounded by fibrous $\mathrm{Si}$ rich phase as shown in Figure 6 when processed by the L-PBF process. A similar microstructure has been reported for AlSi7Mg processed by the L-PBF process [30]. Apart from the fibrous network, Si particles are also dispersed inside the matrix, which may be

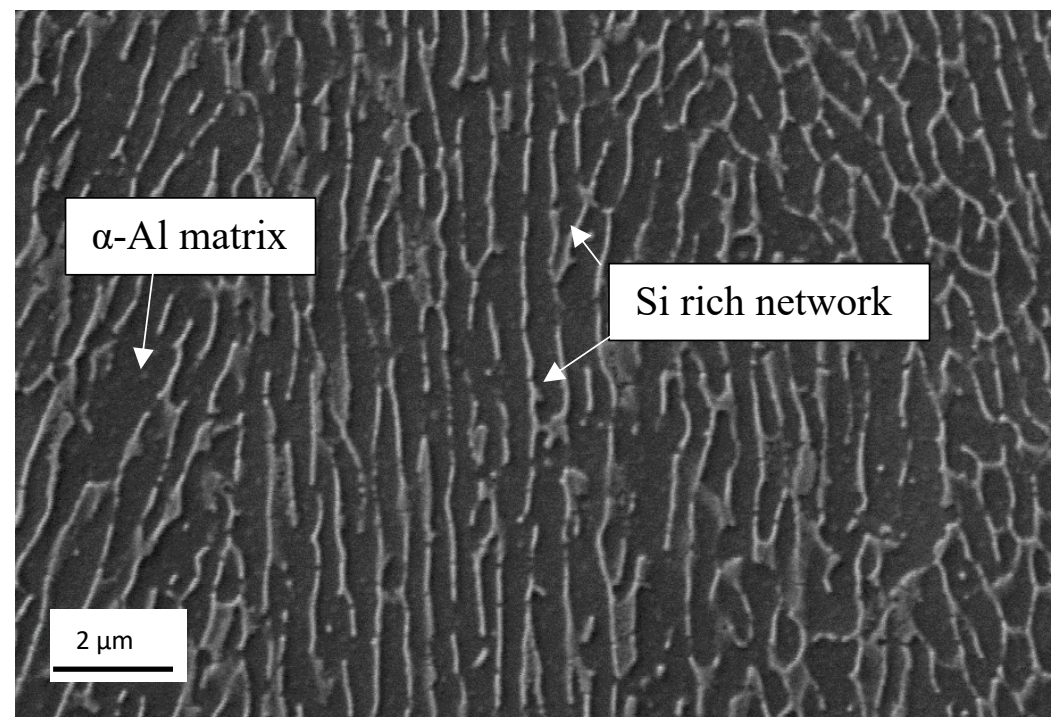


precipitated from the supersaturated $\alpha$-Al matrix afterward due to heat dissipation during part fabrication. The Si content in the $\alpha-\mathrm{Al}$ matrix is higher than the eutectic composition under equilibrium conditions. The non-equilibrium solidification conditions due to rapid cooling lead to a supersaturated $\alpha-\mathrm{Al}$ matrix or pseudo eutectic composition. Indeed, the high cooling rate in the L-PBF process develops a large undercooling at the solidification front, which doesn't provide enough time for Si precipitation [31]. Therefore, high content of Si is retained in the cellular or columnar $\alpha$-Al matrix and leaving residual $\mathrm{Si}$ at the grain boundaries. Also, Dinda et al. [32] reported that the amount of Si content in the Al matrix increases with solidification velocity.

\subsubsection{Optical micrograph of Scan tracks}

The complex pattern of the scan tracks can arise due to different scanning parameters. For example, the woven-like melt pools result from applied scanning rotation between the consecutive layers, as shown in Figure 7a. The scan tracks are also not continuous in the cross-section due to variation in the melt pool dimensions especially melt pool depth. The optical micrograph of etched as-built samples shows contrast at the edges of the scan tracks. This contrast arises because the cell size is of the order of the wavelength of the visible light.

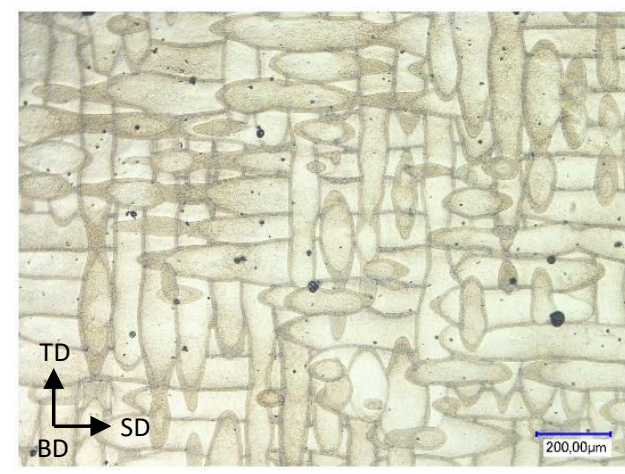

(a)

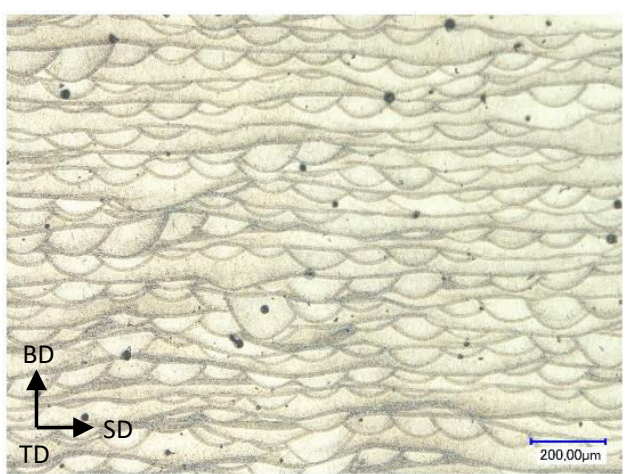

(b)

Figure 7: Optical micrograph of as-built C_5*5_45 (a) transverse, (b) building direction. (SD: Scanning direction, TD: Transverse direction, BD: Building direction)

Also, the melt pool boundary is visible (See Figure 7b). 
The unique microstructure in the melt pool is due to the variation of cooling rate and thermal gradient across the melt pool. Epitaxial growth of the $\alpha$-Al phase along the thermal gradient is evident in Figure 8: the melt pool shows elongated dendritic morphology in the longitudinal or building direction and cellular morphology in the transverse cross-section. Grain formation during solidification depends on the $G / R$ parameter where $G$ is temperature gradient and $R$ cooling rate. Thus, depending on the evolution of $\mathrm{G} / \mathrm{R}$, different morphologies, planar, cellular, columnar, can be obtained. When the laser melts the powder, and the previous layers, many small grains nucleate at the melt pool's border due to the high value of $G$ [33], [34]. These newly nucleated grains competitively grow into columnar or cellular grains due to higher $\mathrm{G} / \mathrm{R}$ value. Crystallographic texture results indicate that these grains have a specific orientation, i.e., $<100>$ along with the scanning direction. Some of the grains remain equiaxed at the border of the melt pool. There is also a possibility of forming equiaxed grains at the top of the melt pool due to columnar to equiaxed transition (CET). CET can be observed during the laser treatment when the nucleation of large equiaxed grains occurs in the constitutionally undercooled liquid in front of the dendritic columnar front, as reported by

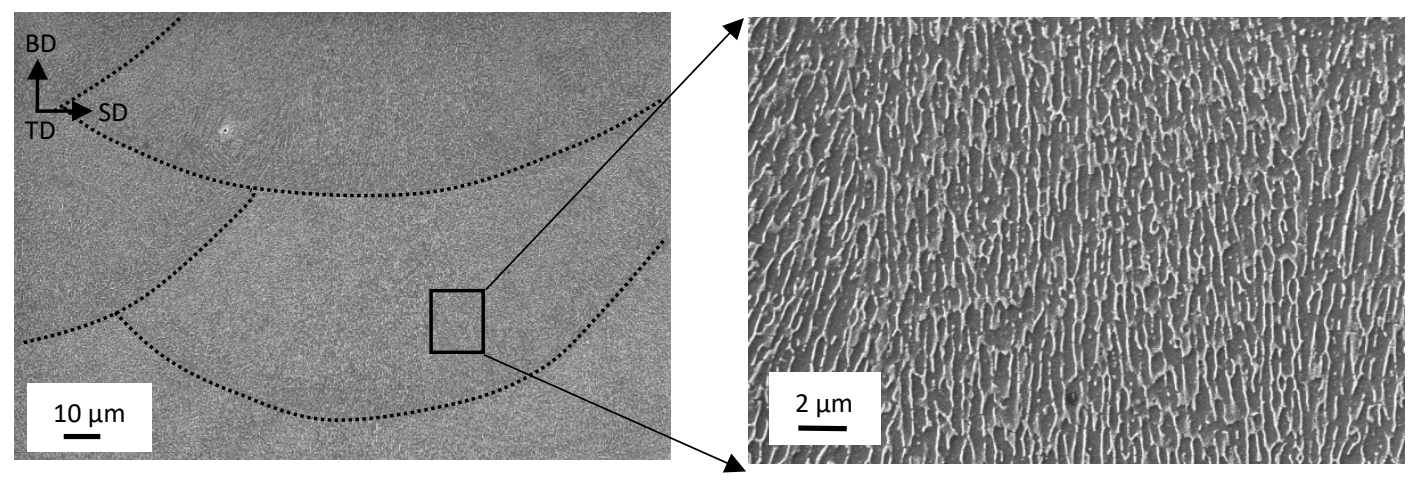

(a)

(b)

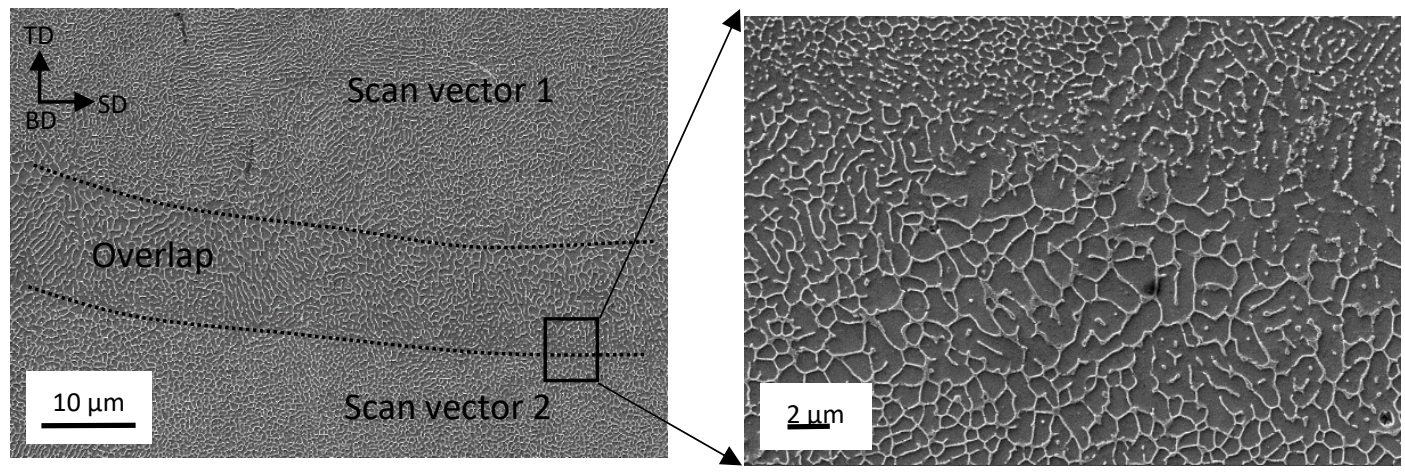

(c)

(d)

Figure 8: SEM micrographs of S_10_67 sample in $(a, b)$ building direction and $(c, d)$ transverse direction. 
[35]. However, the CET equiaxed grains at the top of the melt pool are not visible as the subsequent remelting passes destroy them.

Three distinct regions are highlighted in the melt pool micrographs, (a) a fine grains region, (b) a coarser grains region, and (c) a heat affected zone (HAZ). The different regions of the grains are related to undercooling variation due to the Gaussian distribution of laser energy: the laser energy is higher at the center of the melt pool and lowers at the edges and then $G$ is higher at the center of the melt pool and lower at the edges of the melt pool. The factor $G^{*} R$ determines the fineness of the grains. Therefore $G^{*} \mathrm{R}$ is higher at the center of the melt pool leading to fine cellular or columnar microstructure. On the contrary, a lower value of $\mathrm{G}^{*} \mathrm{R}$ leads to coarser microstructure at the edges of the melt pool [33], [36]. The transition from fine to coarse microstructure is clearly visible in Figure 9. Another possible reason for coarser microstructure could be the formation of a semi-solid-state during the melting of successive passes. A semi-solid state or mushy zone can be generated when the temperatures are between the liquidus and solidus [37]. As reported by previous studies, the obtained semi-
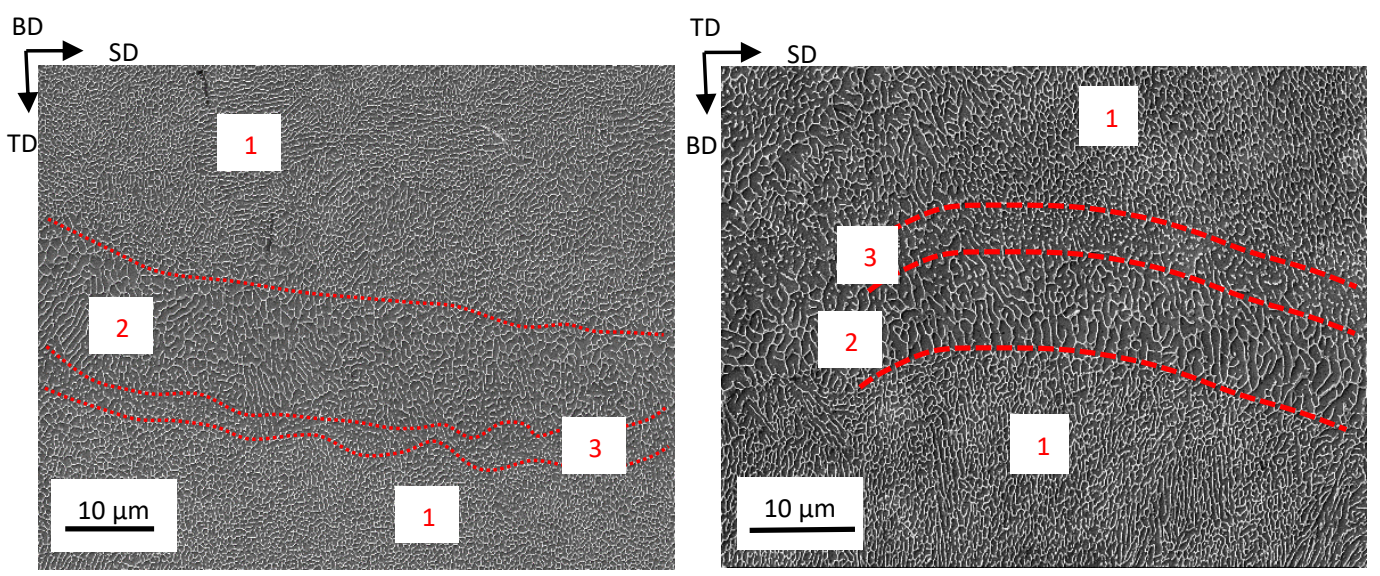

Figure 9: SEM images of the melt pool for sample showing the three distinct regions i.e. fine (1), coarse (2) and $H A Z$ (3) regions.

solid state can lead to coarser microstructure [38], [39].

Heat affected zone is another distinct region along the melt pool boundary. It can be characterized by a discontinuous silicon phase, which may be due to the increasing rate of silicon [33], [36]. When the laser melts the next layer, the temperature is lower than the solidus in the previous layer and acts as the heat treatment for the beneath layer creating a HAZ. Due to high scanning speeds and high cooling rates, the time for the HAZ to maintain that temperature is too less. Therefore, we only observe a small strip of HAZ with randomly 
dispersed Si cells. The temperature in the HAZ allows the precipitation of Si particles from the supersaturated $\alpha$-Al matrix, which is formed due to higher cooling rates. As Si particles form and grow, the Si network finally disappears [36], [40].

\subsubsection{Cell Size and cooling rates}

The cell size variation inside the melt pool regions is measured using the ImageJ software from SEM images. The Figure 10 presents the variation inside a melt pool obtained with the presented strategy: it is observed that the cell size varies concerning the location within the melt pool. The cooling rate based on the cell size is calculated using Equation 1. For example, it is found that there is a higher cooling rate of $1.8 * 10^{6} \mathrm{~K} / \mathrm{s}$ at the top of the melt pool where the cell size is smaller, and the lower cooling rate of $1.3^{*} 10^{5} \mathrm{~K} / \mathrm{s}$ in the coarser region (Figure
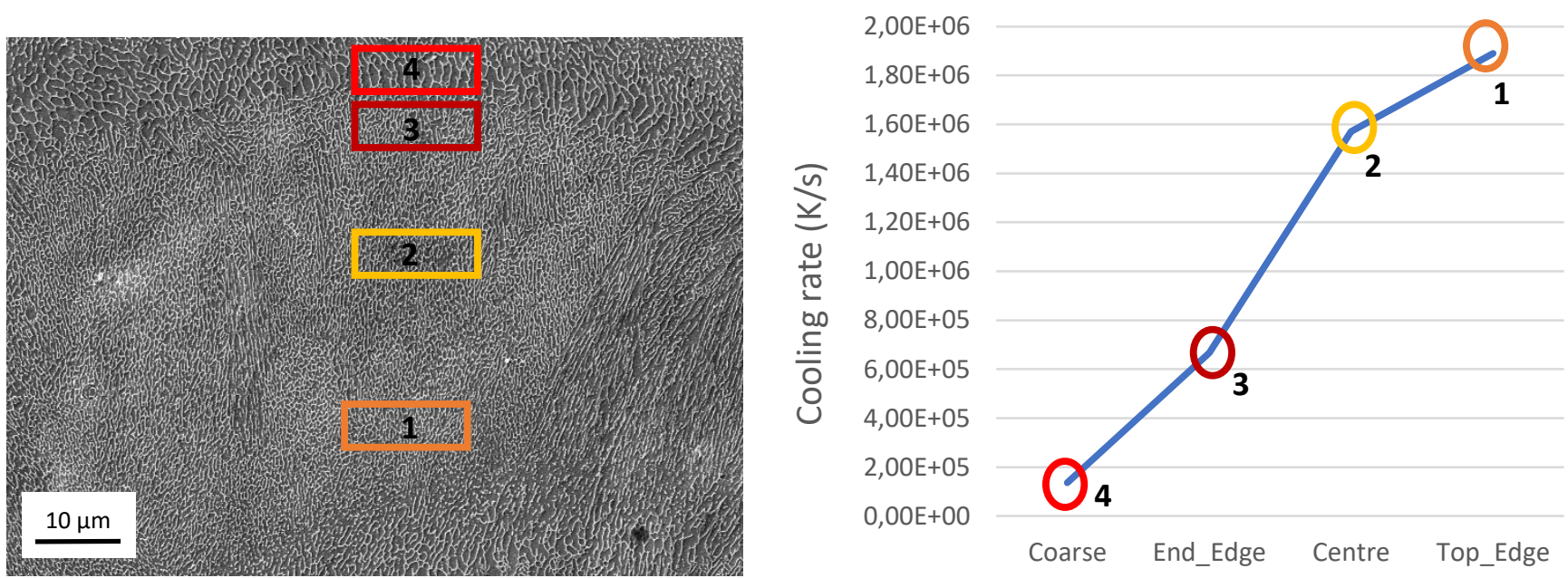

Figure 10: Example of cooling rates variation inside the melt pool. Also, the numbers mark the location of the measurements of the cells.

10b). Also, the cell size and cooling are calculated for different scanning parameters (Figure 11): it is noticed that there is no significant influence of scan strategy and its parameters, such as scan vector length and rotation, on the cooling rates and cell sizes. 

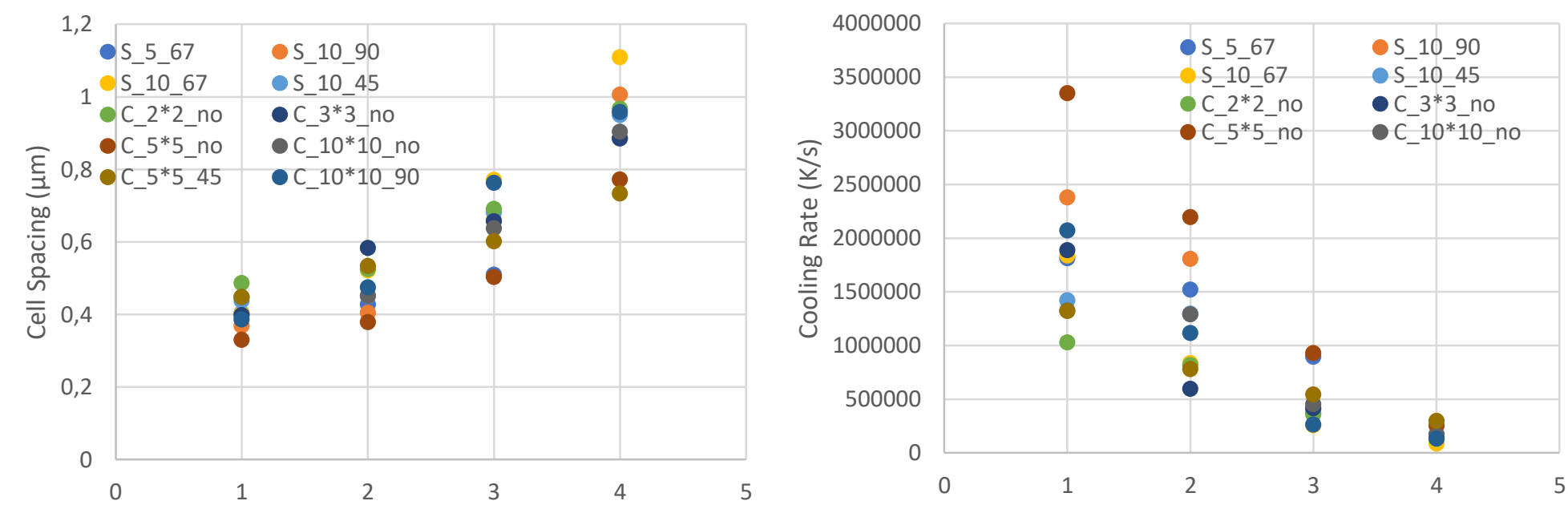

Figure 11: (a) Cell spacing and (b) calculated cooling rates. In X-axis, the numbers denote the location within the melt pool i.e. 1: Top edge, 2: Centre, 3: Bottom edge, 4: Coarse region of the melt pool. Also marked in Figure 10.

The cooling rate and cell size are then predominately dependent on the power and scan, as already reported by Farshidianfar et al. [41] for direct deposition process.

\subsubsection{Grain Morphology}

Figure 12 shows the grain morphology of the SLMed AlSi7Mg0.6 alloy samples obtained by EBSD analysis. It can be observed that the microstructure is mainly composed of elongated grains, which are parallel to the building direction. Because of the growth of elongated grains towards the center of the melt pool and the existence of small equiaxed grains, some of the melt pool boundaries could be distinguished. In the vicinity of the melt pool boundary, small equiaxed grains appear. Grains are measured using a boundary misorientation angle definition of $2^{\circ}$. The crystallites of size less or equal to two map pixels are ignored to reduce noise in the data.

There is no significant observable difference in mean grain size for different scanning strategies as shown in Figure 13. The average grain size for the samples S_5_67, S_10_90, S_10_45, S_10_67, C_3*3_no, C_2*2_no, C_10*10_no, C_5*5_no, C_10*10_90, and C_5*5_45 is $12.88 \mu \mathrm{m}, 10.46 \mu \mathrm{m}, 13.39 \mu \mathrm{m}, 13.81 \mu \mathrm{m}, 12.02 \mu \mathrm{m}, 12.36 \mu \mathrm{m}, 12.38 \mu \mathrm{m}$, $12.41 \mu \mathrm{m}, 13.71 \mu \mathrm{m}$, and $10.21 \mu \mathrm{m}$, respectively. 


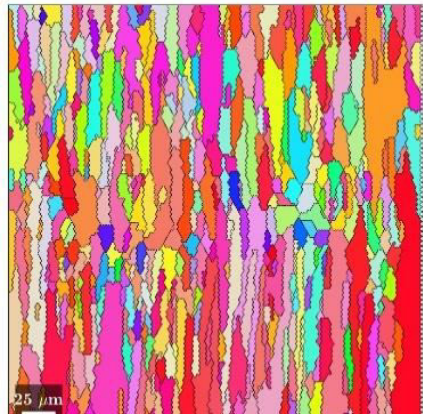

(a)

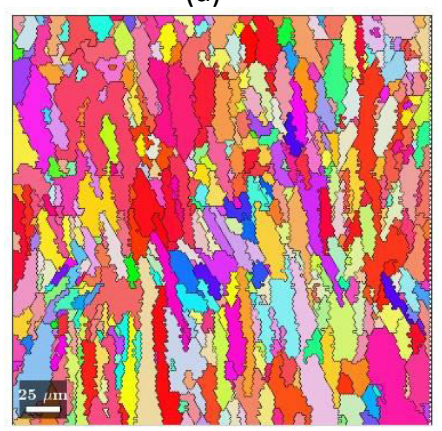

(e)

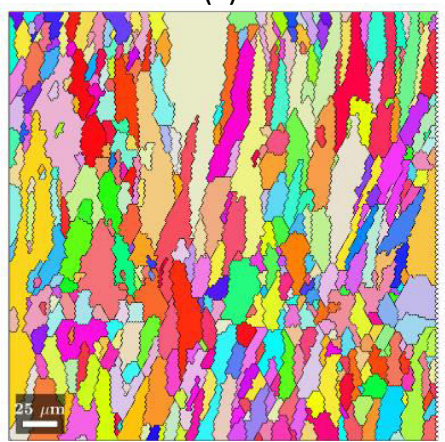

(i)

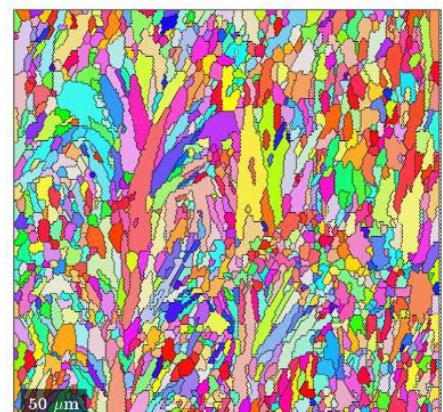

(b)

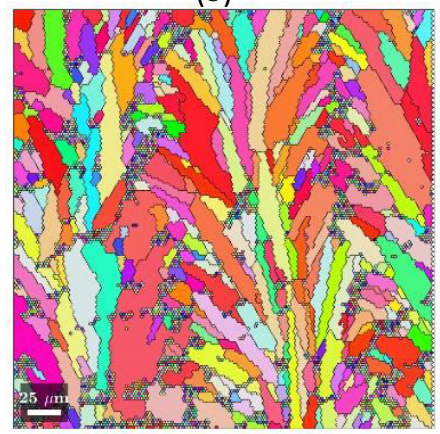

(f)

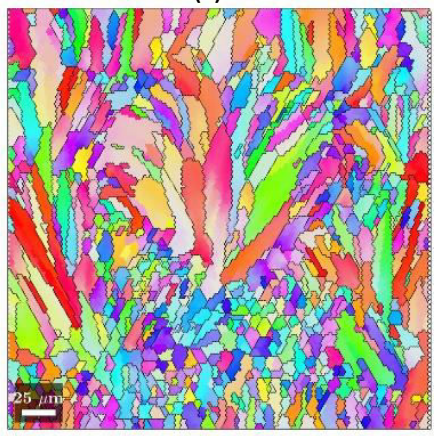

(j)

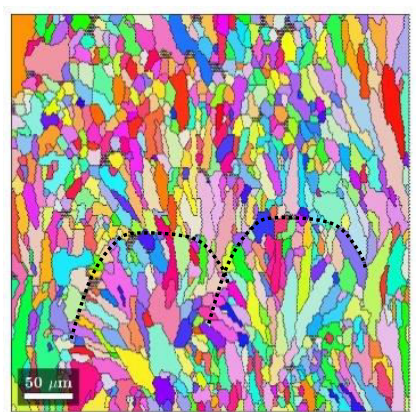

(c)

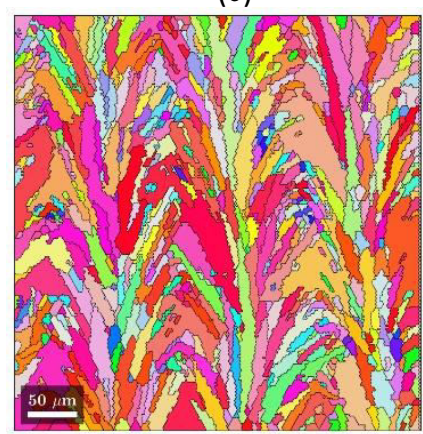

(g)

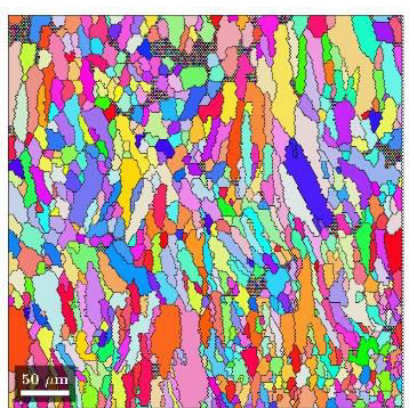

(d)

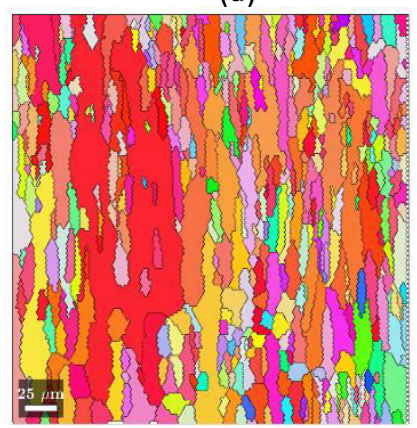

(h)
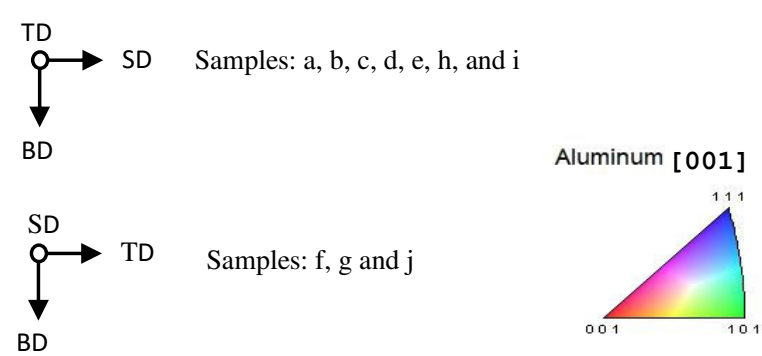

Aluminum [001]$$
\text { . }
$$ .}

Figure 13: IPF images showing the grain morphology for samples (a)S_5_67, (b)S_10_90, (c)S_10_45, (d)S_10_67, (e)C_3*3_no, (f) C_2*2_no, (g) C_10*10_no, (h) C_5*5_no, (i) C_10*10_90, and (j) C_5*5_45.

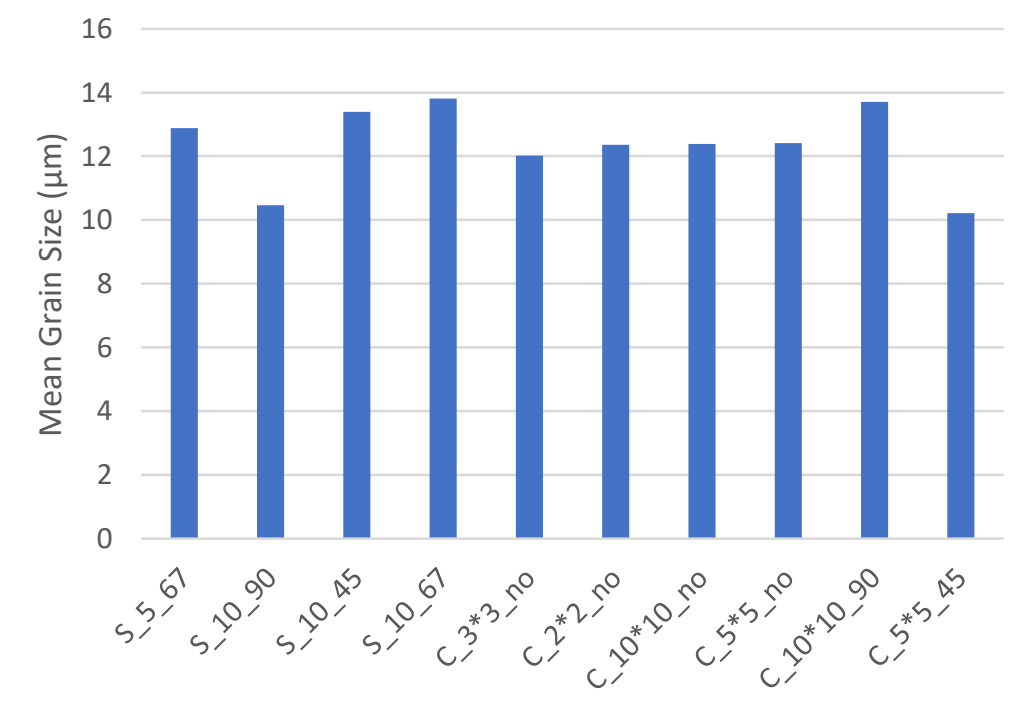

Figure 12: Average grain size. 


\subsubsection{Grain Misorientation Angle}

The grain boundaries misorientation angle are also considered for different scanning strategies. The misorientation values higher than $15^{\circ}$ are regarded as the high angle grain boundaries (HAGBs), and those lower than $15^{\circ}$ are termed as lower angle grain boundaries (LAGBs). The fraction of LAGBs is higher compared to the HAGBs in the samples (Figure 14). The boundary misorientation distribution has no significant difference between the samples. A high density of LAGBs is present in the columnar $\alpha$-Al grains, as also observed by

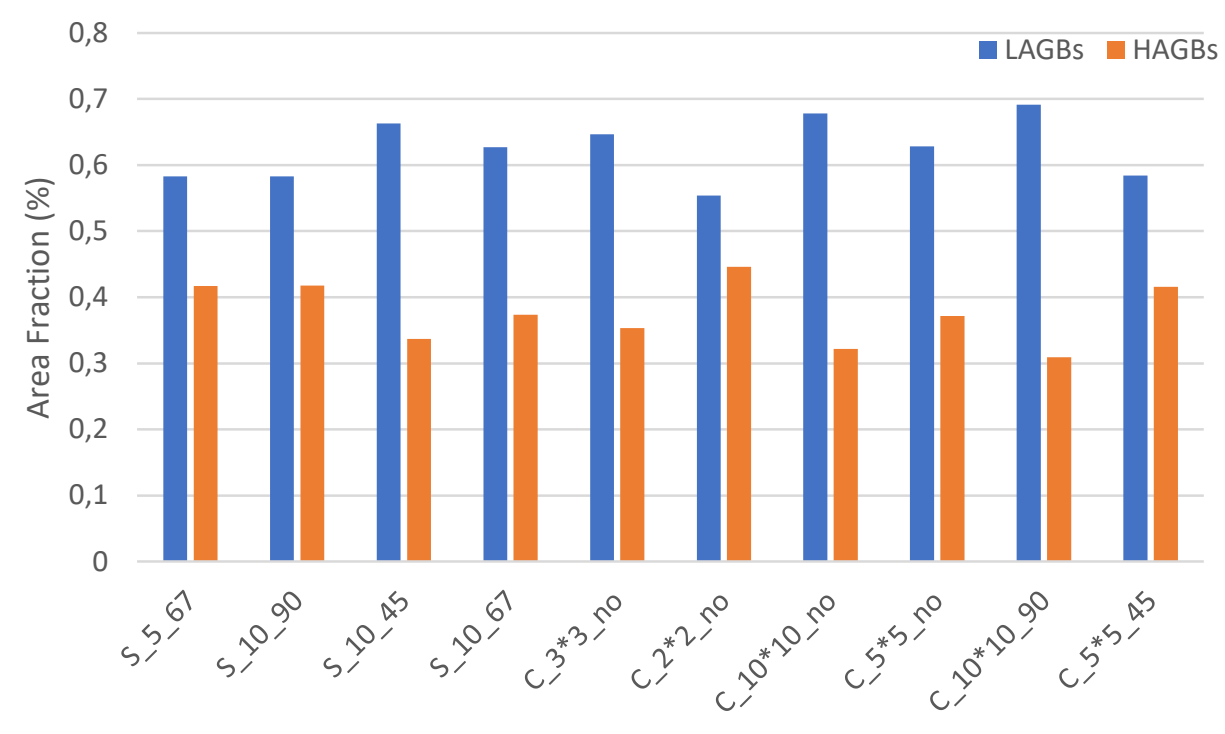

Figure 14: Area fraction of LAGBs and HAGBs.

Takata et al. [40]. A fine substructure within the $\alpha$-Al grains is responsible for the highdensity LAGBs.

\subsubsection{Crystallographic Texture}

\section{a. Texture Index}

During the solidification, there are preferred orientations in each grain that grow much faster than other orientations. This preferred growth during the solidification of the melt pool leads to crystallographic texture in the printed part. For example, $<100>$ fiber texture parallel to the scanning direction is expected because the melt pool is elongated in the scanning direction, and solidification starts along that direction. But the crystallographic orientation can be controlled and modified according to the processing parameters such as scanning direction, laser power, scanning speed, and layer rotation angle [42]. For instance, Liu et al. [8] reported the effect of laser power on the crystallographic texture evolution in A1Si10Mg alloys. Similarly, Thijs et al. [33] reported that the strong fiber texture in AlSi10Mg alloy changes to weak cubic texture by rotating each layer $90^{\circ}$ from the previous. In this research, we studied 
the effect of scanning strategy, rotation angle, and scan vector length on the crystallographic texture evolution.

There are only a few studies that investigated the crystallographic texture in Al Alloys. Usually, the crystallographic textures do not contribute much to overall anisotropy in the material, which is an attribute related to the orientation of the parts.

Since the Al has FCC crystal structure, columnar grains usually prefer $<100>$ texture [42], [43]. Texture can be categorized into two, i.e., Micro-texture and Macro-texture. The macrotexture can be measured by X-rays, neutrons, electron diffraction techniques. Whereas the micro-texture can be studied using the scanning electron microscopy-based electron backscatter diffraction technique (SEM-EBSD).

The overall texture index (TI) is given by the texture index, which is expressed as

$$
T I=\int_{\text {Eulerspace }}(\mathrm{f}(g))^{2} d g
$$

Equation 4

Where $f$ denotes the orientation distribution function of the Euler space coordinates $g$ [44]. The texture index (TI) defines the volume fraction of the crystals having a particular orientation compared to others. If $\mathrm{TI}=0$, this means there is no crystal having this specific

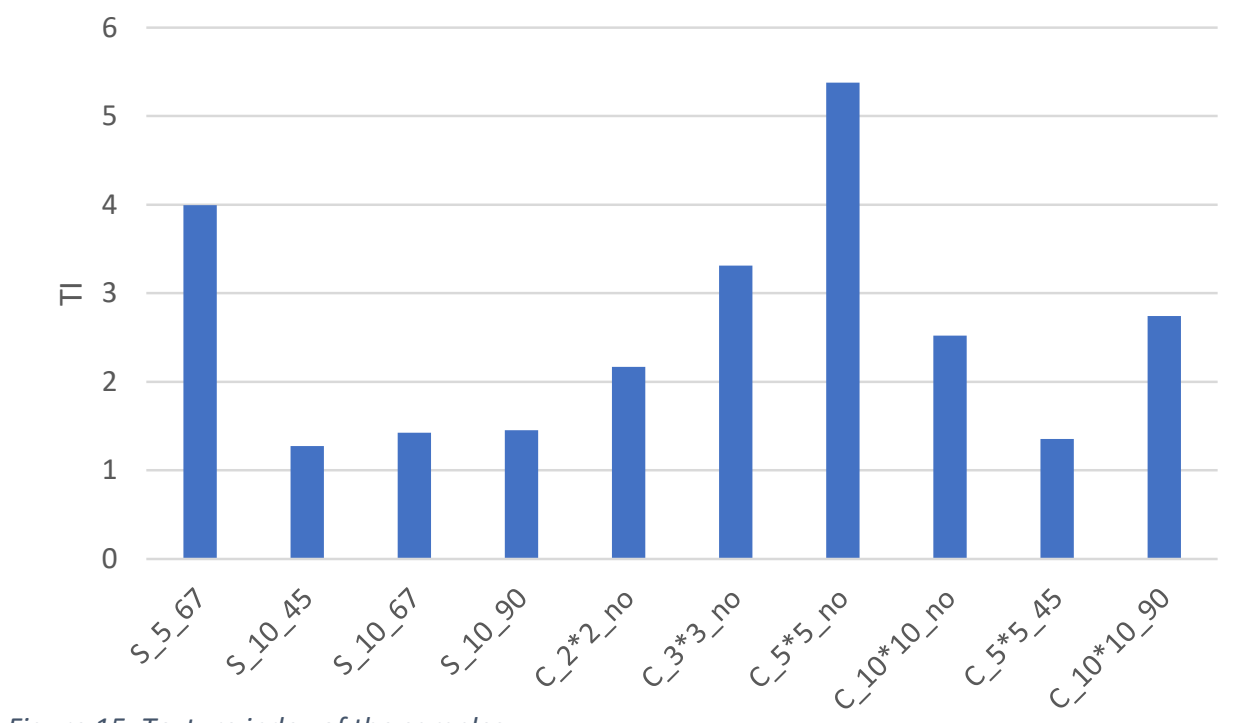

Figure 15: Texture index of the samples.

orientation. If $T I=1$, then it denotes one crystal for each possible orientation, also termed as "random distribution." If $T I>1$ for example, $T I=3$, then it defines the number of crystals with a particular orientation that is 3 times the utterly random distribution. TI values are read in 
terms of "multiples of random orientation (MRD)," higher the TI value, the more textured the material is. From Figure 15 (calculated on the obtained EBSD data), it can be observed that for chessboard strategy, TI increases with an increase in the island sizes until $5 \mathrm{~mm}$ and then drops for an island of size $10 \mathrm{~mm}$. However, comparing samples C_5*5_no and C_5*5_45, it can be noted that the TI decreases significantly from 5.3 (no rotation) to 1.3 (application of $45^{\circ}$ rotation between consecutive layers). Incase of stripes, we observed that $T I$ is close to 1 for a stripe length of $10 \mathrm{~mm}$ for all rotation angle, while $T I$ is close to 4 when the stripe length is reduced to half.

Mackenzie plot is the representation of the misorientation distribution for a cubic sample with a random texture. Suppose at any misorientation angle the frequency of the actual distribution is higher than the corresponding frequency in the Mackenzie distribution. In that case, it

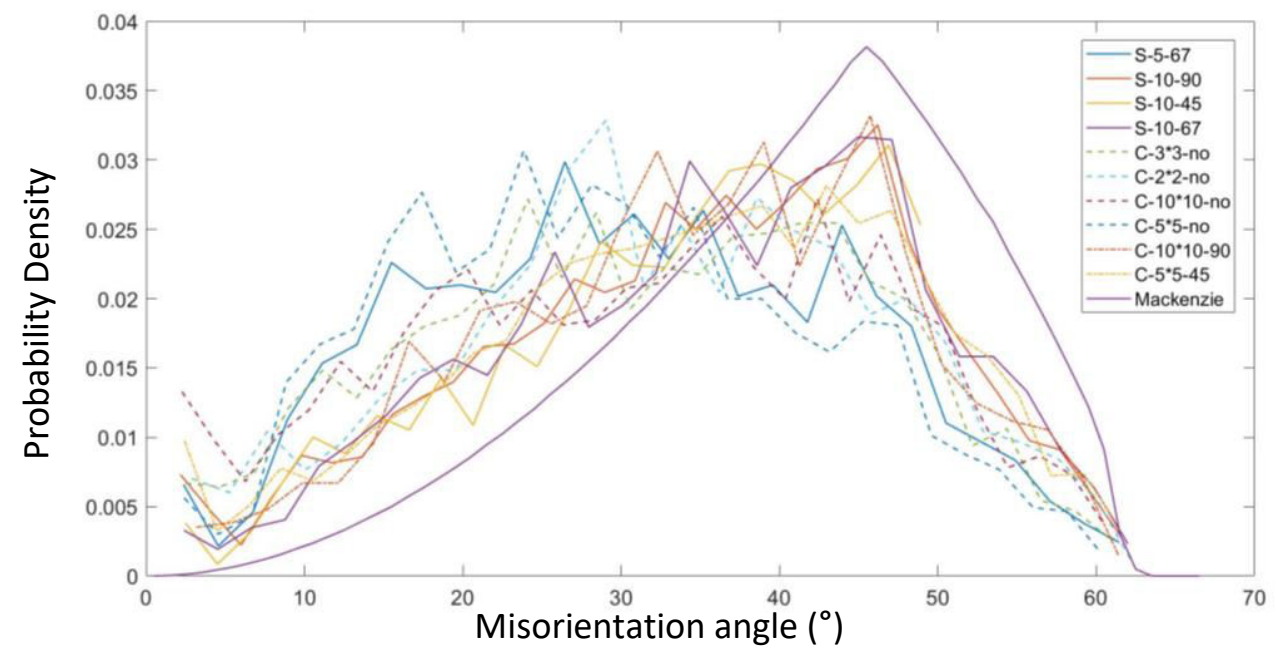

Figure 16: Mackenzie plot comparison.

means that the material has texture in one of the preferred orientations. It can be seen in Figure 16 that all the samples show the actual frequency distribution higher than the Mackenzie distribution, especially for misorientation angles $<35^{\circ}$. So, it can be concluded that all the samples have a preferred orientation.

b. Inverse Pole Figure Intensity

Pole figure intensity is a measure of how dissimilar the crystals are when compared to random orientation distribution. Although the calculation is different from TI, the pole intensity measures crystallographic anisotropy or texture in the material by using SEM-EBSD. 
C_2*2_no, C_3*3_no, C_5*5_no, and C_10*10_no samples scanned with varying scan vector length, and the scanning angle is kept constant for each layer. It is noticed that a strong $<100>$ along the scanning direction is observed, and weaker $<110>$ texture along building
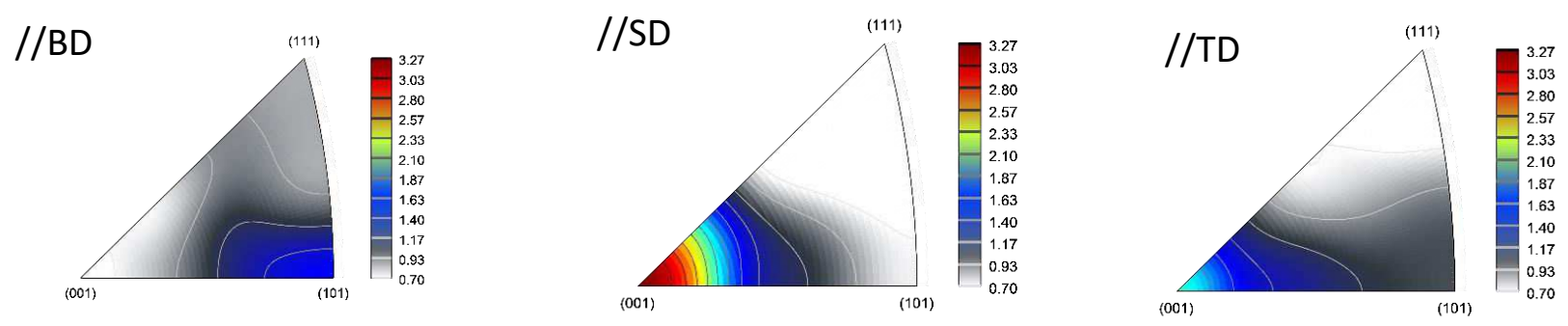

(a)
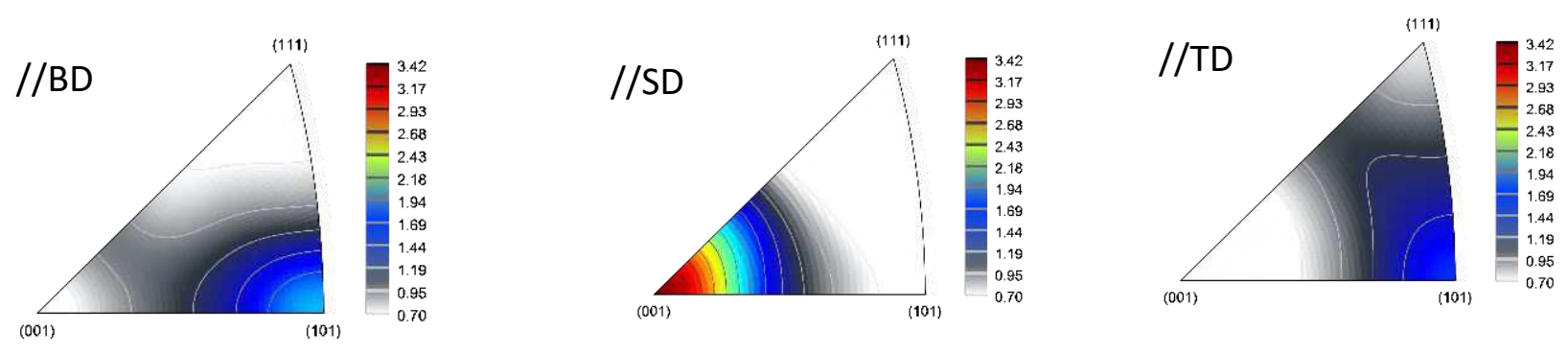

(b)
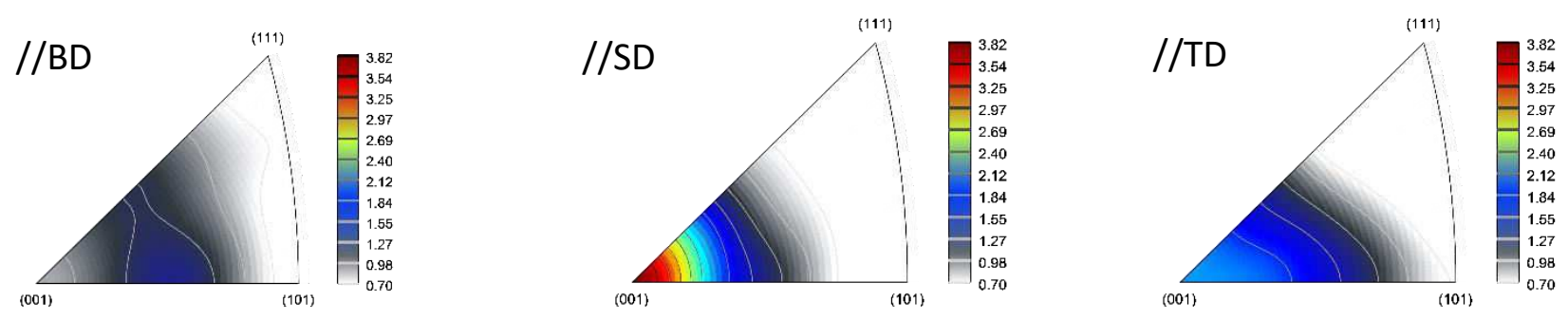

(c)
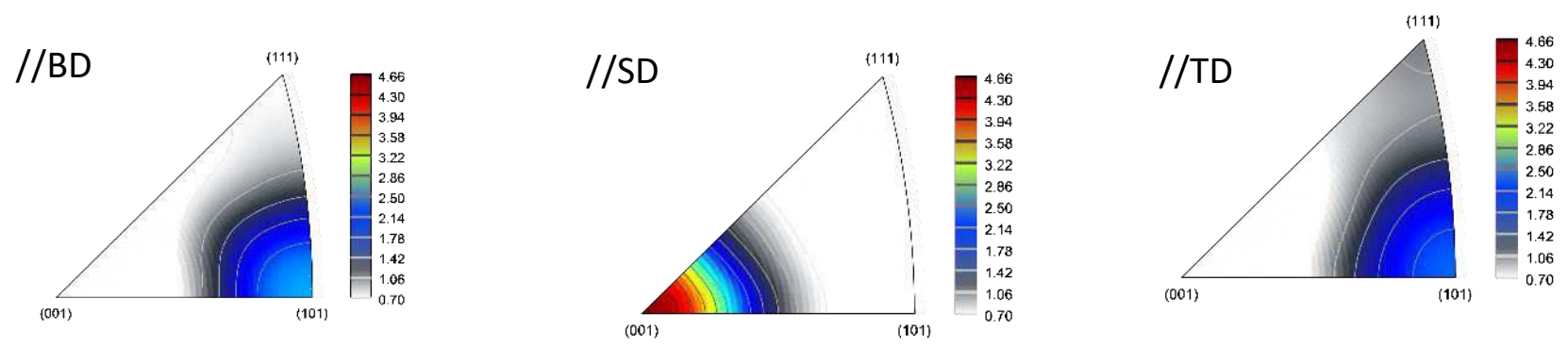

(d)

Figure 17: Intensity pole figures for samples (a) C_2*2_no, (b) C_3*3_no, C_5*5_no, and C_10*10_no. 
texture arise, as shown in Figure 17 (except for Figure 17c). The pole figure intensity increases as the scan vector length increases for $<100>$ direction parallel to the scanning direction.

In samples S_5_67 and S_10_67, the scan vector length changes from $5 \mathrm{~mm}$ to $10 \mathrm{~mm}$ while the rotation angle in consecutive layers is kept constant at $67^{\circ}$. Like chessboard strategy, there is strong $<100>$ along the scanning direction. Still, the overall texture intensity is lesser for bigger scan vectors than chessboard cases, as shown in Figure 18.
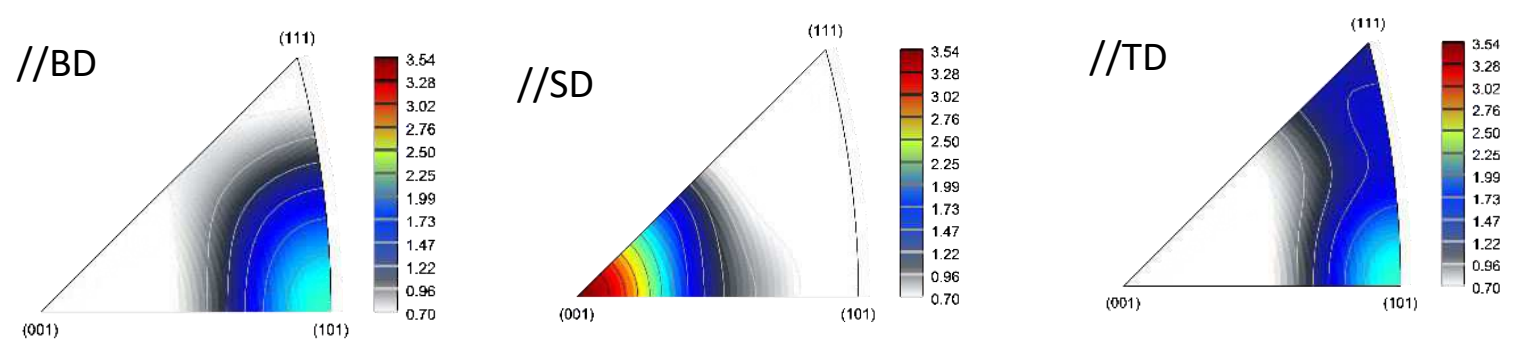

(a)
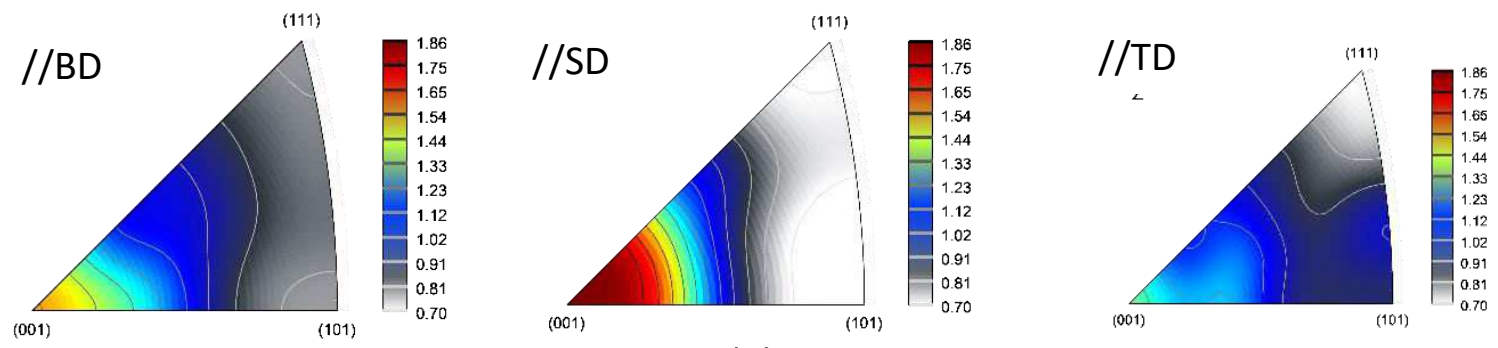

(b)

Figure 18: Intensity pole figures for samples (a) S_5_67 and (b) S_10_67.

Effect of rotation angle

Samples S_10_45, S_10_67, and S_10_90 are printed with the same scanning vector length, but the rotation angle between the layers is changed to $45^{\circ}, 67^{\circ}$, and $90^{\circ}$, respectively. All the samples show $<100>$ texture along the scanning direction, but a significant texture pattern is also observed for building direction, as shown in Figure 19. 

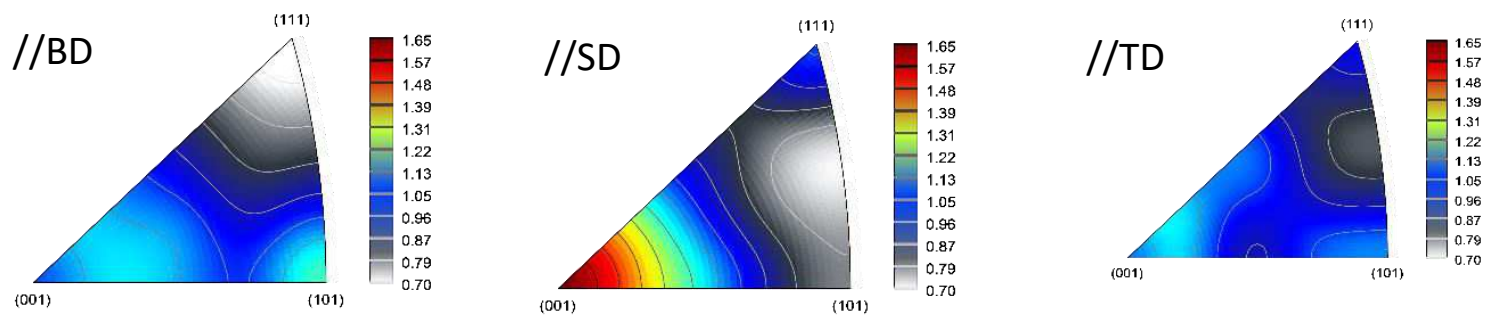

(a)
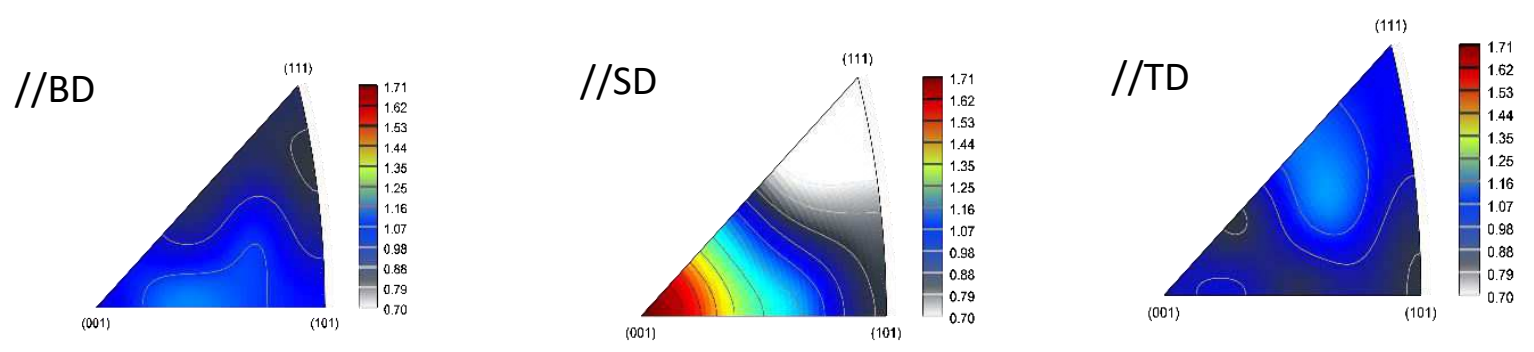

(b)

Figure 19: Intensity pole figures for samples (a) S_10_45, and (b) S_10_90.

Samples C_5*5_no and C_10*10_no are compared with samples C_5*5_45 and C_10*10_90 (Figure 20) to investigate the rotation effect in chessboard strategy. As observed earlier, there is $<100>$ texture parallel to the scanning direction for all the samples. But the pole intensity decreases from 4.66 to 1.59 when the $\mathrm{C} \_5^{*} 5$ nno rotated by $45^{\circ}\left(\mathrm{C} \_5^{*} 5 \_45\right)$. Also, the texture
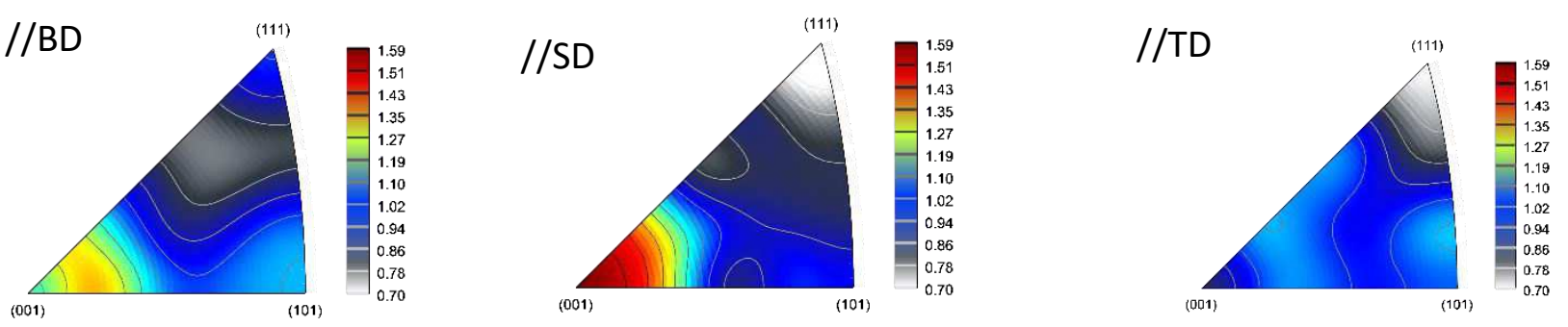

(a)
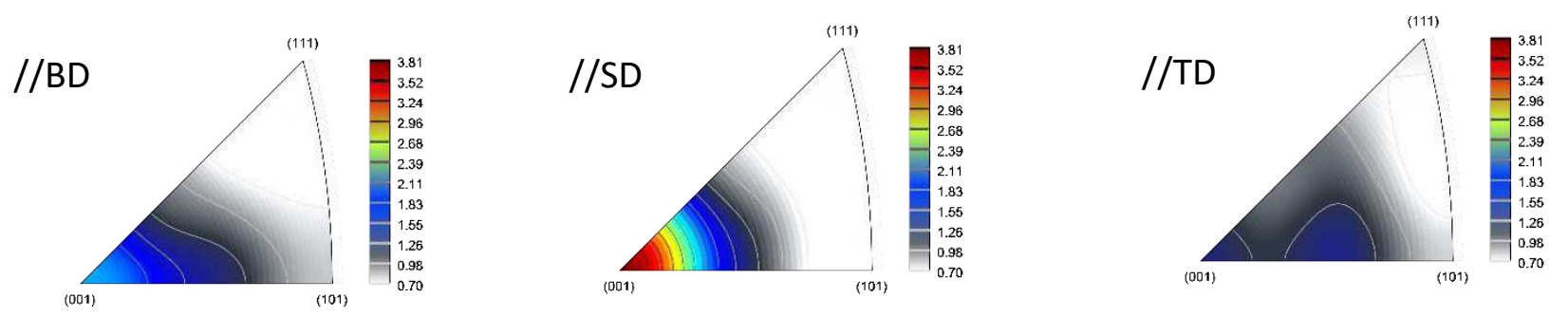

(b)

Figure 20: Intensity pole figures for samples (a) C_5*5_45, and (b) C_10*10_90. 
$<101>$ parallel to building direction for non-rotated samples decreases, and texture $<100>$ starts to arise for building direction. The same can be seen for the sample C_10*10_no, where the pole intensity decreases by applying a rotation of $90^{\circ}$ between layers. Also, the $<100>$ texture orientation parallel to building direction starts to arise. So, it can be concluded that applying rotation between layers can decrease the texture intensity in the material. In other words, it lowers the intensity of crystallographic anisotropy in the material.

Overall, Stripes (except S_5_67 and C_5*5_45) shows the lower texture intensity in $<100>$ direction parallel to scanning direction compared to chessboard strategy, which is also confirmed by the texture index discussed in the previous section.

\subsection{Fractography}

In the fracture micrographs, it is noticed that the effect of scan vector length and rotation is not significantly visible. However, there is a clear difference in the fracture behavior in stripes and chessboard scanning strategy. Figure 21 shows the micrographs of the fracture surfaces of the tensile samples for stripes and chessboard strategies. In chessboard strategy, the samples fail like a brittle fracture linked to the presence of elongated porosity at the island junction, as shown in Figure $21 \mathrm{~b}$.

In stripes, the fracture looks like a ductile fracture. In Figure 21a, the micro-voids or microporosity on the edge of the samples could be the crack initiation site. It is noticed that the tearing occurs along the melt pool boundaries. The evidence of fracture due to Si particles
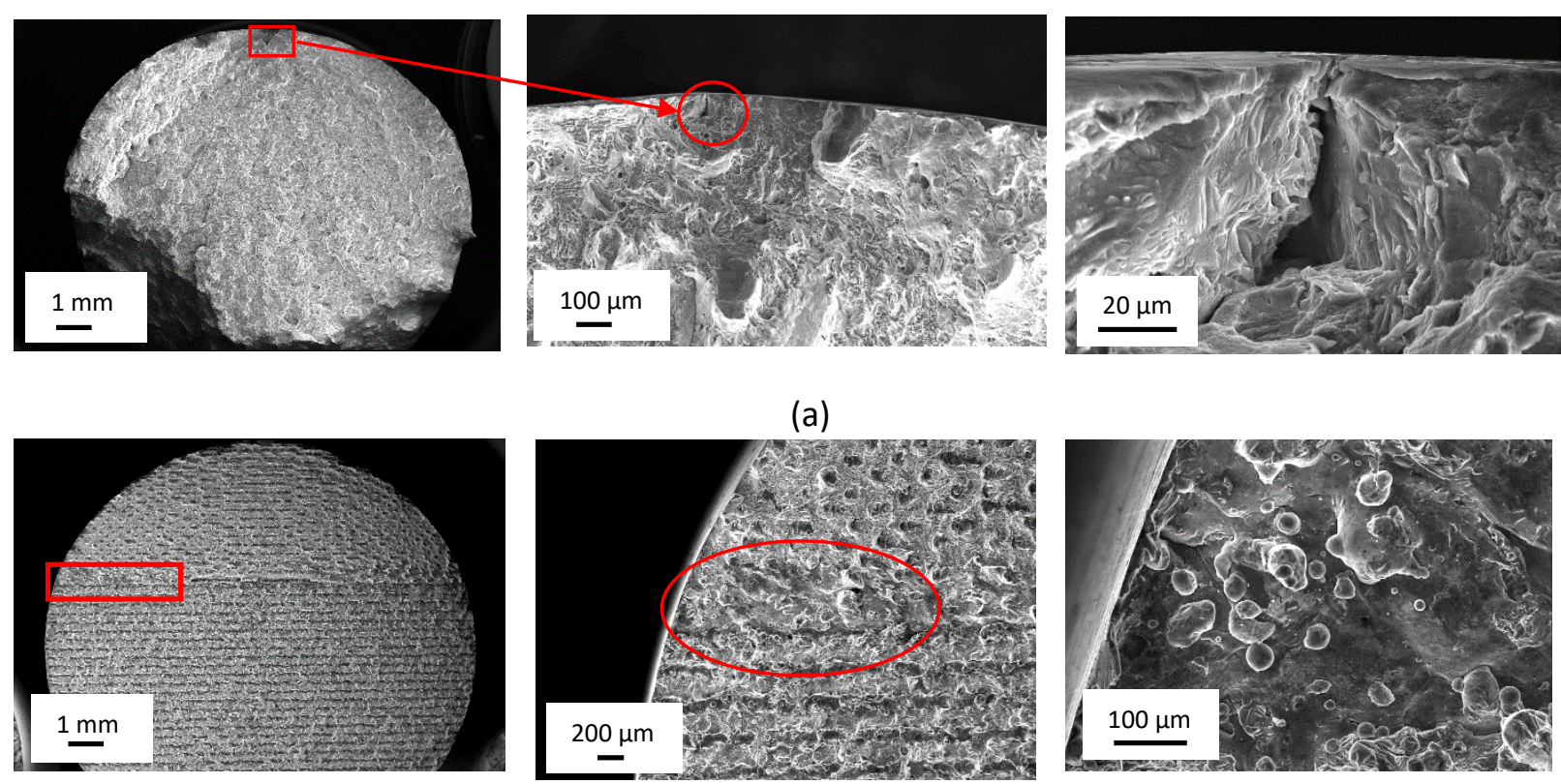

(b)

Figure 21: Fracture surface for samples (a) S_10_67, and (b) C_10*10_90 at different magnifications. 
at the center of the grains is not found.

\subsection{Residual Stresses}

Residual stresses are internal stresses that remain in part after the completion of the manufacturing process. The type and nature of the residual stresses are subjected to the entire manufacturing route used to produce that part. The uncontrolled relaxation of the residual stresses can have a detrimental effect on the manufactured part. The residual stresses can act as additional stress when the part is subjected to service conditions. This can have a severe impact on the lifetime of the part. Sometimes, the residual stresses are beneficial and desired. For example, the compressive residual stresses at the surface of the part can increase resistance to fatigue or corrosion under stress. Tensile residual stresses are penalizing and correspond to areas at risk of premature failure. The samples used for the study of residual stresses are cylinders with a diameter of $16 \mathrm{~mm}$ and length of $55 \mathrm{~mm}$ (attached from the manufacturing plate).

the residual stresses are measured at surface and at $2 \mathrm{~mm}$ depth, for three locations: at two edges (start: represents where the printing started and end: represents where the scanning vector ends) and in the center of the bar (Figure 22a)

The measurement directions are circumferential direction $\left(0^{\circ}\right)$ and axial direction $\left(90^{\circ}\right)$ (Figure 22b)

It is important to note that the measurement uncertainty is estimated at $\pm 7 \%$ in case of a $95 \%$ confidence interval. 


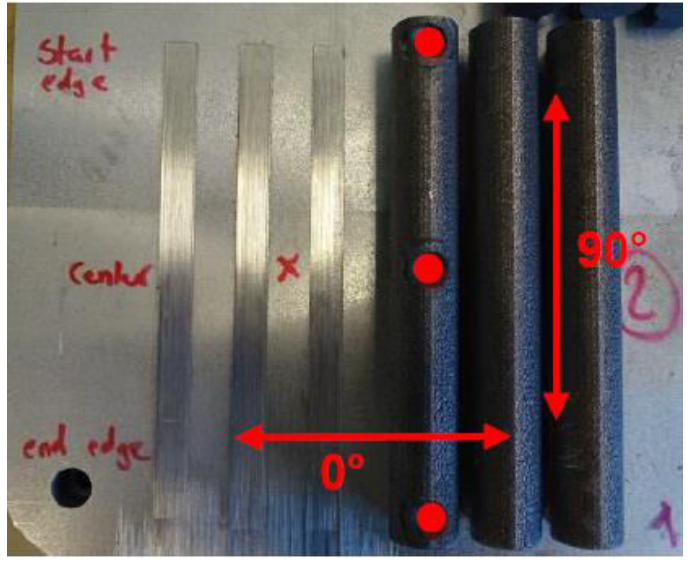

(a)

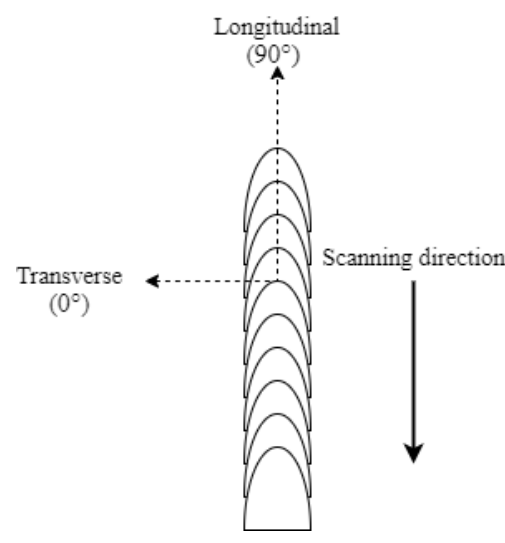

(b)

Figure 22: (a) Location of the measurement points i.e. Start, Centre, and End (marked in red circles), (b) schematic of the measurement directions based on laser scan track.

\subsubsection{At Surface}

The residual stress at the surface in the circumferential direction of all the samples are very low tensile or low compressive stresses, as shown in Figure 23. In contrast, we could observe very high tensile stresses in the axial direction (Figure 23). Similarly, the stresses are very

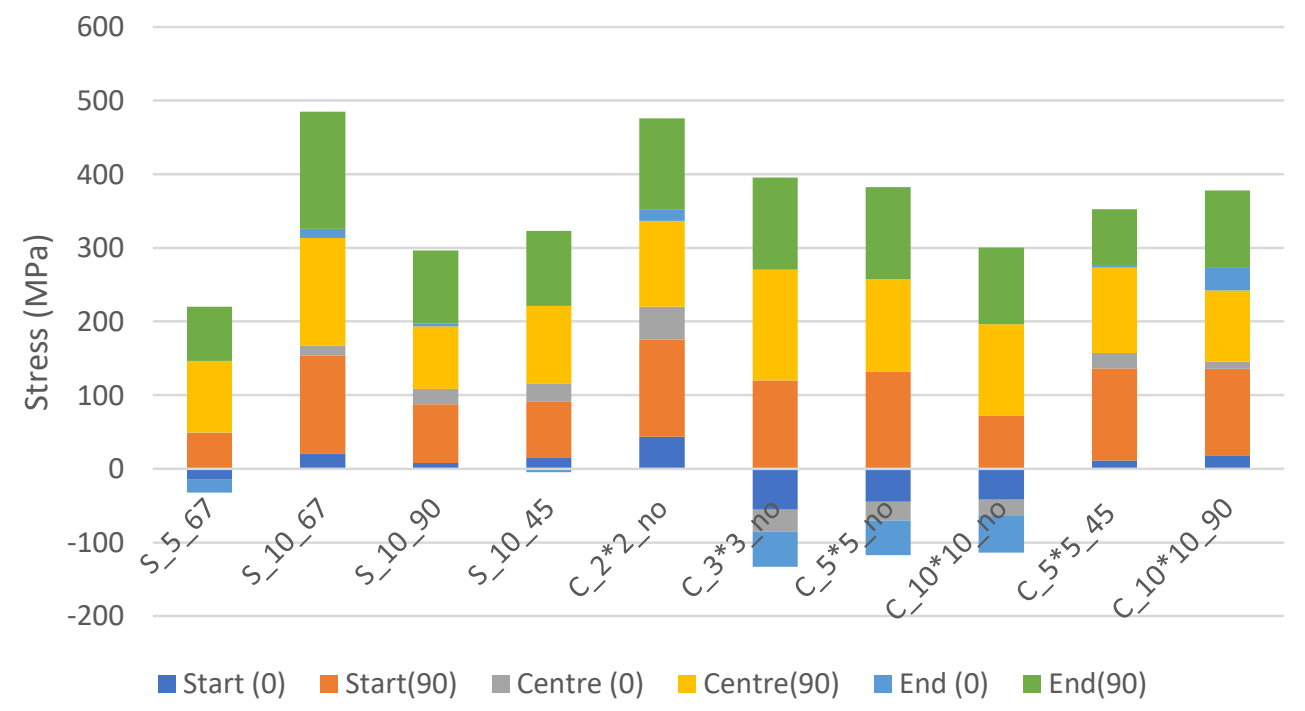

Figure 23: Change in residual stresses based on the location of the measurement points at the surface of the parts.

high in the centre of the part for both directions for all the samples. Typically, the start edge has higher stresses than the end edge except for C_3*3_no and $C_{-} 10 * 10 \_90$ for transverse direction, in contrast the same could not be observed for longitudinal direction. However, the difference in the start and end edges is not very significant compared to the center region. Based on the above results, we can confirm that the residual stresses are higher in the 
longitudinal direction at the surface of the part, which is also the direction of laser printing (Figure 22b). Therefore, there are higher stresses along the melt pool length axis compared to the width axis. No significant effect of scanning strategies could be observed in residual stresses.

\subsubsection{At $2 \mathrm{~mm}$ depth}

Similar to results at the surface, the residual stresses are higher in the longitudinal direction than in the transverse direction (Figure 24). However, the stresses are higher at $2 \mathrm{~mm}$ depth in comparison with the stresses at the surface. It is essential to notice no significant variation in the stresses at the edges and center of the part for both directions (except S_10_45).

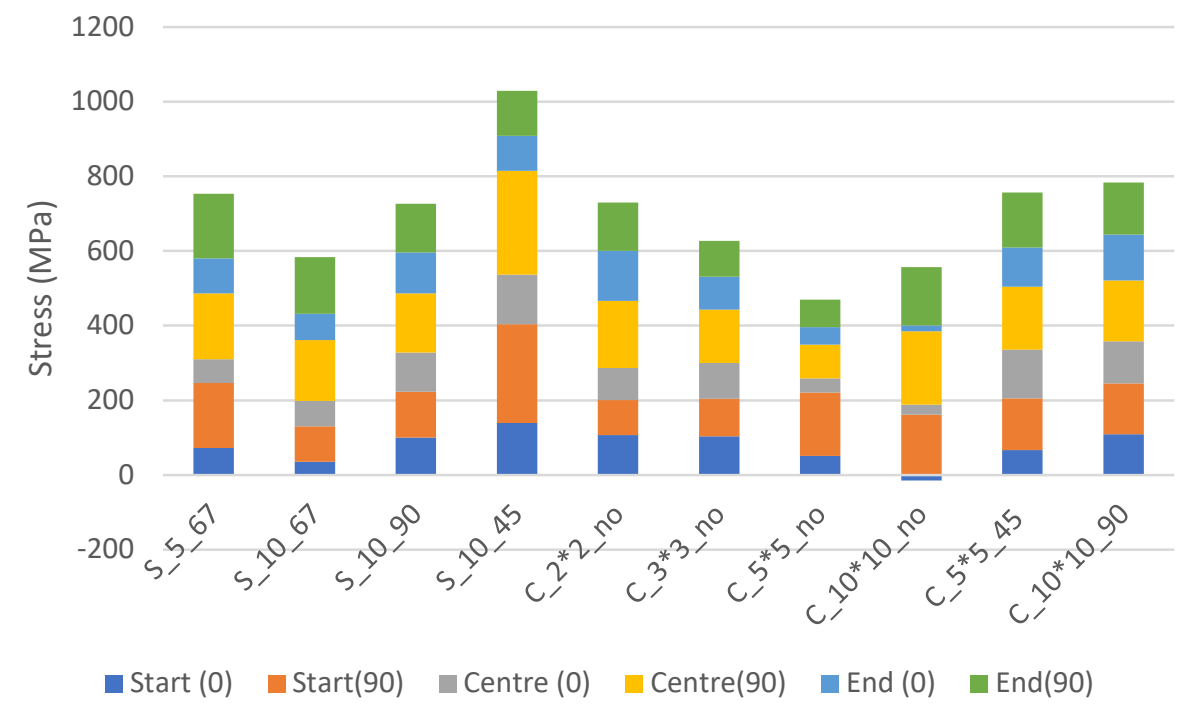

Figure 24: Change in residual stresses based on the location of the measurement points at the 2 $\mathrm{mm}$ depth of the parts.

\section{Conclusions}

The scanning strategy plays a pivotal role in influencing the final part's overall mechanical and microstructural properties. The findings of this study can be summarized as follows:

1. The stripes have higher densification than chessboard strategy due to the present lack of fusion porosity at the junction of the islands. Also, the stripes with rotation exhibit good mechanical properties such as tensile strength and hardness.

2. Microstructurally, both equiaxed and columnar grains are observed, which is linked to a higher value of $\mathrm{G}$ at the melt boundary. The same microstructure has been reported for AlSi10Mg alloys as well. Three distinct regions within the melt pool are 
highlighted and investigated, i.e., fine, coarse, and HAZ zone. A Si-rich phase existed as a fibrous structure in a pseudo eutectic structure.

3. Cooling rates are estimated using the cell size within the melt pool, and it can be concluded that the cooling rates vary within the melt pool due to rapid cooling. The center of the melt pool has the highest cooling rates, and it decreases gradually at the end edge of the melt pool. However, no significant distinction is observed w.r.t. different scanning parameters.

4. The EBSD analysis shows that the grains are preferentially ordered in $<100>$ crystal direction parallel to scanning direction as reported in the literature for other Al alloys. But the Texture Index varies with varying the scan vector length. In the case of a chessboard, TI increases with an increase in island size until $5 \mathrm{~mm}$. Also, rotation angle has a significant effect on lowering the overall TI of the material. Overall, the stripes have lower TI compared to the chessboard strategy.

5. The fracture surface of the samples is investigated using SEM analysis. It is observed that the chessboard samples show a brittle-like fracture which can also be confirmed with the elongation \% obtained during mechanical properties. The brittle fracture is linked to the presence of the porosities that act as fracture initiation sites. In comparison, stripes showed typical ductile fracture behavior. The micro-voids or microporosity on the edge of the samples could be the crack initiation site. It is noticed that the tearing occurs along the melt pool boundaries.

6. Finally, the residual stresses at the surface and $2 \mathrm{~mm}$ depth are studied along the scanning direction, i.e., longitudinal and transverse direction. For all the samples, the residual stresses are higher in the longitudinal direction compared to the transverse direction. The highest stresses observed at the center of the samples as compared to the two edges. The higher residual stresses are observed for $2 \mathrm{~mm}$ depth. But no significant pattern is observed w.r.t. to scan vector length and rotation.

\section{Acknowledgments}

This work was conducted as part of the "ENABLE" project funded by the European Union's Marie Sklodowska-Curie Actions (MSCA) Innovative Training Networks (ITN) H2020MSCA-ITN-2017 under the grant agreement Number 764979. Authors would like to acknowledge the contribution of Mr. Bega Jeremie, ENSAM, Bordeaux for his continuous support and help provided for experimental analysis. 


\section{Statements \& Declarations}

\section{Funding}

This work was supported by the European Union's Marie Sklodowska-Curie Actions (MSCA) Innovative Training Networks (ITN) H2020-MSCA-ITN-2017 under the grant agreement Number 764979. Author Pinku Yadav is the recipient of the above-mentioned funding.

\section{Competing Interests}

The authors have no relevant financial or non-financial interests to disclose.

\section{Author Contributions}

All authors contributed to the study conception and design. Material preparation, data collection and analysis were performed by Pinku Yadav, and Corinne Arvieu. The first draft of the manuscript was written by Pinku Yadav and all authors commented on previous versions of the manuscript. All authors read and approved the final manuscript.

\section{Availability of data and material (data transparency)}

No Applicable

Code availability (software application or custom code)

Not Applicable

Ethics approval (include appropriate approvals or waivers)

Authors confirm the novelty of the reported work and confirm that it is not submitted to any other journal.

Consent to participate (include appropriate statements)

Authors give consent to participate.

Consent for publication (include appropriate statements)

Authors give consent for publication.

\section{References}

[1] W. Xiong et al., 'Effect of selective laser melting parameters on morphology, microstructure, densification and mechanical properties of supersaturated silver alloy', Mater. Des., vol. 170, p. 107697, 2019.

[2] Y. Lu et al., 'Study on the microstructure, mechanical property and residual stress of SLM Inconel-718 alloy manufactured by differing island scanning strategy', Opt. Laser Technol., vol. 75, pp. 197-206, 2015.

[3] F. Trevisan et al., 'On the selective laser melting (SLM) of the AlSi10Mg alloy: process, microstructure, and mechanical properties', Materials, vol. 10, no. 1, p. 76, 2017.

[4] J. Jhabvala, E. Boillat, T. Antignac, and R. Glardon, 'On the effect of scanning strategies in the selective laser melting process', Virtual Phys. Prototyp., vol. 5, no. 2, pp. 99-109, 2010.

[5] L. N. Carter, C. Martin, P. J. Withers, and M. M. Attallah, 'The influence of the laser scan strategy on grain structure and cracking behaviour in SLM powder-bed fabricated nickel superalloy', J. Alloys Compd., vol. 615, pp. 338-347, 2014. 
[6] P. Köhnen, M. Létang, M. Voshage, J. H. Schleifenbaum, and C. Haase, 'Understanding the process-microstructure correlations for tailoring the mechanical properties of L-PBF produced austenitic advanced high strength steel', Addit. Manuf., vol. 30, p. 100914, 2019.

[7] Y. M. Arısoy, L. E. Criales, T. Özel, B. Lane, S. Moylan, and A. Donmez, 'Influence of scan strategy and process parameters on microstructure and its optimization in additively manufactured nickel alloy 625 via laser powder bed fusion', Int. J. Adv. Manuf. Technol., vol. 90, no. 5, pp. 1393-1417, 2017.

[8] X. Liu, C. Zhao, X. Zhou, Z. Shen, and W. Liu, 'Microstructure of selective laser melted AlSi10Mg alloy', Mater. Des., vol. 168, p. 107677, 2019.

[9] A. J. Dunbar et al., 'Development of experimental method for in situ distortion and temperature measurements during the laser powder bed fusion additive manufacturing process', Addit. Manuf., vol. 12, pp. 25-30, 2016.

[10] B. Cheng, S. Shrestha, and K. Chou, 'Stress and deformation evaluations of scanning strategy effect in selective laser melting', Addit. Manuf., vol. 12, pp. 240-251, 2016.

[11] A. V. Gusarov, M. Pavlov, and I. Smurov, 'Residual stresses at laser surface remelting and additive manufacturing', Phys. Procedia, vol. 12, pp. 248-254, 2011.

[12] L. Parry, I. A. Ashcroft, and R. D. Wildman, 'Understanding the effect of laser scan strategy on residual stress in selective laser melting through thermo-mechanical simulation', Addit. Manuf., vol. 12, pp. 1-15, 2016.

[13] J.-P. Kruth, J. Deckers, E. Yasa, and R. Wauthlé, 'Assessing and comparing influencing factors of residual stresses in selective laser melting using a novel analysis method', Proc. Inst. Mech. Eng. Part B J. Eng. Manuf., vol. 226, no. 6, pp. 980-991, Jun. 2012, doi: 10.1177/0954405412437085.

[14] P. Mercelis and J.-P. Kruth, 'Residual stresses in selective laser sintering and selective laser melting', Rapid Prototyp. J., 2006.

[15] J. C. Pereira, E. Gil, L. Solaberrieta, M. San Sebastián, Y. Bilbao, and P. P. Rodríguez, 'Comparison of AlSi7Mg0. 6 alloy obtained by selective laser melting and investment casting processes: Microstructure and mechanical properties in as-built/as-cast and heat-treated conditions', Mater. Sci. Eng. A, vol. 778, p. 139124, 2020.

[16] R. A. O. Heng, S. GIET, Y. Kun, W. U. Xin-hua, and C. DAVIES, 'The influence of processing parameters on aluminium alloy A357 manufactured by selective laser melting [J]', Mater. Des., vol. 109, pp. 334-346, 2016.

[17] K. V. Yang, P. Rometsch, C. H. J. Davies, A. Huang, and X. Wu, 'Effect of heat treatment on the microstructure and anisotropy in mechanical properties of A357 alloy produced by selective laser melting', Mater. Des., vol. 154, pp. 275-290, 2018.

[18] D. Buchbinder, W. Meiners, N. Pirch, K. Wissenbach, and J. Schrage, 'Investigation on reducing distortion by preheating during manufacture of aluminum components using selective laser melting', J. Laser Appl., vol. 26, no. 1, p. 012004, 2014.

[19] A. B. Spierings, M. u Schneider, and R. Eggenberger, 'Comparison of density measurement techniques for additive manufactured metallic parts', Rapid Prototyp. J., 2011.

[20] I. O. for Standardization, Metallic Materials: Vickers Hardness Test. Test Method. International Organization for Standardization, 2000.

[21] A. Standard, 'E8/E8M-13a, standard test method for determining volume fraction by systematic manual point count', Aug ASTM Int. West Conshohocken PA, 2013.

[22] D. Rosenthal, 'Mathematical theory of heat distribution during welding and cutting', Weld. J., vol. 20, pp. 220-234, 1941.

[23] M. Tang, P. C. Pistorius, S. Narra, and J. L. Beuth, 'Rapid Solidification: Selective Laser Melting of AlSi10Mg', JOM, vol. 68, no. 3, pp. 960-966, Mar. 2016, doi: 10.1007/s11837-015-1763-3.

[24] N. J. Grant, 'Rapid solidification of metallic particulates', JOM, vol. 35, no. 1, pp. 20-27, 1983.

[25] D. Bouchard and J. S. Kirkaldy, 'Equations and Specification of Predictive Procedures', Met. Mater Trans B, vol. 28, no. 4, pp. 651-663, 1996.

[26] H. J. Hegge and J. T. M. De Hosson, 'Solidification structures during laser treatment', Scr Met., vol. 24, pp. 593-599, 1990. 
[27] H. Ali, H. Ghadbeigi, and K. Mumtaz, 'Effect of scanning strategies on residual stress and mechanical properties of Selective Laser Melted Ti6Al4V', Mater. Sci. Eng. A, vol. 712, pp. 175187, 2018.

[28] 'Alloy Specifications', Stena Aluminium. https://www.stenaaluminium.com/Aluminium-alloysand-services/alloy-specifications/ (accessed Oct. 02, 2021).

[29] J. T. O. de Menezes, E. M. Castrodeza, and R. Casati, 'Effect of build orientation on fracture and tensile behavior of A357 Al alloy processed by Selective Laser Melting', Mater. Sci. Eng. A, vol. 766, p. 138392, 2019.

[30] L. Liang, X. Pan, G. Wang, H. Zhang, and H. Zhang, 'Microstructure and mechanical properties of selective laser melted AlSi7Mg', in Journal of Physics: Conference Series, 2021, vol. 1939, no. 1, p. 012041.

[31] J. L. Murray and A. J. McAlister, 'The Al-Si (aluminum-silicon) system', Bull. Alloy Phase Diagr., vol. 5, no. 1, p. 74, 1984.

[32] G. P. Dinda, A. K. Dasgupta, and J. Mazumder, 'Evolution of microstructure in laser deposited Al-11.28\% Si alloy', Surf. Coat. Technol., vol. 206, no. 8-9, pp. 2152-2160, 2012.

[33] L. Thijs, K. Kempen, J.-P. Kruth, and J. Van Humbeeck, 'Fine-structured aluminium products with controllable texture by selective laser melting of pre-alloyed AlSi10Mg powder', Acta Mater., vol. 61, no. 5, pp. 1809-1819, 2013.

[34] J. Liu and A. C. To, 'Quantitative texture prediction of epitaxial columnar grains in additive manufacturing using selective laser melting', Addit. Manuf., vol. 16, pp. 58-64, 2017.

[35] M. Gäumann, C. Bezencon, P. Canalis, and W. Kurz, 'Single-crystal laser deposition of superalloys: processing-microstructure maps', Acta Mater., vol. 49, no. 6, pp. 1051-1062, 2001.

[36] W. Li et al., 'Effect of heat treatment on AlSi10Mg alloy fabricated by selective laser melting: Microstructure evolution, mechanical properties and fracture mechanism', Mater. Sci. Eng. A, vol. 663, pp. 116-125, 2016.

[37] S. Nafisi, D. Emadi, M. T. Shehata, and R. Ghomashchi, 'Effects of electromagnetic stirring and superheat on the microstructural characteristics of Al-Si-Fe alloy', Mater. Sci. Eng. A, vol. 432, no. 1-2, pp. 71-83, 2006.

[38] J. K. Chen, H. Y. Hung, C. F. Wang, and N. K. Tang, 'Effects of casting and heat treatment processes on the thermal conductivity of an Al-Si-Cu-Fe-Zn alloy', Int. J. Heat Mass Transf., vol. 105, pp. 189-195, 2017.

[39] M. H. Mulazimoglu, R. A. L. Drew, and J. E. Gruzleski, 'Solution treatment study of cast Al-Si alloys by electrical conductivity', Can. Metall. Q., vol. 28, no. 3, pp. 251-258, 1989.

[40] N. Takata, H. Kodaira, K. Sekizawa, A. Suzuki, and M. Kobashi, 'Change in microstructure of selectively laser melted AlSi10Mg alloy with heat treatments', Mater. Sci. Eng. A, vol. 704, pp. 218-228, 2017.

[41] M. H. Farshidianfar, A. Khajepour, and A. P. Gerlich, 'Effect of real-time cooling rate on microstructure in laser additive manufacturing', J. Mater. Process. Technol., vol. 231, pp. 468478, 2016.

[42] D. Manfredi et al., 'Additive manufacturing of Al alloys and aluminium matrix composites (AMCs)', Light Met. Alloys Appl., vol. 11, pp. 3-34, 2014.

[43] N. T. Aboulkhair, I. Maskery, C. Tuck, I. Ashcroft, and N. M. Everitt, 'On the formation of AlSi10Mg single tracks and layers in selective laser melting: Microstructure and nanomechanical properties', J. Mater. Process. Technol., vol. 230, pp. 88-98, 2016.

[44] U. F. Kocks, C. N. Tomé, and H.-R. Wenk, Texture and anisotropy: preferred orientations in polycrystals and their effect on materials properties. Cambridge university press, 1998. 